ARTICLE

Received 4 Dec 2014 | Accepted 15 Jun 2015 | Published 23 Jul $2015 \quad$ DOl: 10.1038/ncomms8817 OPEN

\title{
Controllable synthesis of molybdenum tungsten disulfide alloy for vertically composition-controlled multilayer
}

Jeong-Gyu Song ${ }^{1}$, Gyeong Hee Ryu ${ }^{2}$, Su Jeong Lee ${ }^{3}$, Sangwan Sim¹, Chang Wan Lee ${ }^{1}$, Taejin Choi ${ }^{1}$, Hanearl Jung ${ }^{1}$, Youngjun Kim¹, Zonghoon Lee ${ }^{2}$, Jae-Min Myoung ${ }^{3}$, Christian Dussarrat ${ }^{4}$, Clement Lansalot-Matras ${ }^{5}$, Jusang Park', Hyunyong Choi ${ }^{1} \&$ Hyungjun $\mathrm{Kim}^{1}$

The effective synthesis of two-dimensional transition metal dichalcogenides alloy is essential for successful application in electronic and optical devices based on a tunable band gap. Here we show a synthesis process for $\mathrm{Mo}_{1-x} \mathrm{~W}_{x} \mathrm{~S}_{2}$ alloy using sulfurization of super-cycle atomic layer deposition $\mathrm{Mo}_{1-x} \mathrm{~W}_{x} \mathrm{O}_{y}$. Various spectroscopic and microscopic results indicate that the synthesized $\mathrm{Mo}_{1-x} \mathrm{~W}_{x} \mathrm{~S}_{2}$ alloys have complete mixing of $\mathrm{Mo}$ and $\mathrm{W}$ atoms and tunable band gap by systematically controlled composition and layer number. Based on this, we synthesize a vertically composition-controlled (VCC) $\mathrm{Mo}_{1-x} \mathrm{~W}_{x} \mathrm{~S}_{2}$ multilayer using five continuous super-cycles with different cycle ratios for each super-cycle. Angle-resolved X-ray photoemission spectroscopy, Raman and ultraviolet-visible spectrophotometer results reveal that a VCC $\mathrm{Mo}_{1-x} \mathrm{~W}_{x} \mathrm{~S}_{2}$ multilayer has different vertical composition and broadband light absorption with strong interlayer coupling within a $\mathrm{VCC} \mathrm{Mo}_{1-x} \mathrm{~W}_{x} \mathrm{~S}_{2}$ multilayer. Further, we demonstrate that a $\mathrm{VCC} \mathrm{Mo}_{1-x} \mathrm{~W}_{x} \mathrm{~S}_{2}$ multilayer photodetector generates three to four times greater photocurrent than $\mathrm{MoS}_{2}$ - and $\mathrm{WS}_{2}$-based devices, owing to the broadband light absorption.

\footnotetext{
${ }^{1}$ School of Electrical and Electronic Engineering, Yonsei University, Seoul 120-749, Korea. ${ }^{2}$ School of Materials Science and Engineering, Ulsan National Institute of Science and Technology (UNIST), Ulsan 689-798, Korea. ${ }^{3}$ Department of Materials Science and Engineering, Yonsei University, Seoul 120-749, Korea. ${ }^{4}$ Air Liquide Laboratories, Wadai 28, Tsukuba, Ibaraki 300-4247, Japan. ${ }^{5}$ Air Liquide Laboratories Korea, Yonsei Engineering Research Park, 50 Yonsei-ro, Seodaemun-gu, Seoul 120-749, Korea. Correspondence and requests for materials should be addressed to H.K. (email: hyungjun@yonsei.ac.kr).
} 
T he band gap modulation of two-dimensional (2D) transition metal dichalcogenides (TMDCs) has been intensively studied, because of their various applications in optoelectronic devices such as photodiodes, phototransistors and solar cells ${ }^{1-3}$. It is well known that the band gap of $2 \mathrm{D}$ TMDCs is dependent on the number of layers ${ }^{4-6}$. In addition, alloying 2D TMDCs through the synthesis of $\mathrm{Mo}_{1-x} \mathrm{~W}_{x} \mathrm{~S}_{2}$, $\mathrm{Mo}_{1-x} \mathrm{~W}_{x} \mathrm{Se}_{2}$ or $\mathrm{MoS}_{2 x} \mathrm{Se}_{2(1-x)}$, for example, is another way of practically modulating the band gap. This is an effective approach because of the good thermodynamic stability at room temperature of the alloys, as predicted by theoretical calculations $^{7-14}$. Furthermore, recent studies have shown that a vertically composition-controlled (VCC) 2D TMDCs multilayer is feasible for the high performance optoelectronic devices due to functionality of interlayer such as interlayer transition ${ }^{15-22}$. However, the reported synthesis processes for 2D TMDCs alloy and VCC 2D TMDCs multilayer, such as exfoliation, chemical vapor deposition and transfer, are limited in respect of systematic control of the composition and the number of layers, and clean interface for strong interlayer coupling $9,11,21,23$. Hence, an improved synthesis process for 2D TMDCs alloy and VCC 2D TMDCs multilayer is highly required.

Atomic layer deposition (ALD), which is based on surface reactions between precursors and reactants, has benefits such as high purity, thickness control on the atomic scale and large area uniformity ${ }^{24,25}$. In particular, it is suitable for the synthesis of alloy thin films with precisely controlled composition using the super-cycle method ${ }^{26-28}$. In addition, a continuous super-cycle process with different cycle ratios can produce a VCC multilayer with a clean interface ${ }^{29}$. In a previous report, we have shown that atomically thin, layer-controlled and wafer-level uniform $2 \mathrm{D} \mathrm{WS}$ can be synthesized by sulfurization of ALD $\mathrm{WO}_{3}$ thin films ${ }^{30}$.

Here we report a synthesis method of $\mathrm{Mo}_{1-x} \mathrm{~W}_{x} \mathrm{~S}_{2}$ alloys by sulfurization of super-cycle ALD $\mathrm{Mo}_{1-x} \mathrm{~W}_{x} \mathrm{O}_{y}$ alloy thin films. Using this method, we systematically control the composition and layer number (from mono- to tri-layers) of $\mathrm{Mo}_{1-x} \mathrm{~W}_{x} \mathrm{~S}_{2}$ alloys by controlling the cycle ratio between the ALD $\mathrm{MoO}_{x}$ and $\mathrm{WO}_{3}$. The bandgaps of the $\mathrm{Mo}_{1-}{ }_{x} \mathrm{~W}_{x} \mathrm{~S}_{2}$ alloys are precisely controlled as functions of the composition and layer numbers of each respective alloy, as measured based on the photoluminescence (PL) spectra. Scanning transmission electron microscopy (STEM) shows the mixing of Mo and $\mathrm{W}$ atoms with shared metal atom sites in monolayer $\mathrm{Mo}_{1-x} \mathrm{~W}_{x} \mathrm{~S}_{2}$ alloy. Furthermore, we develop a process to synthesize a VCC $\mathrm{Mo}_{1-x} \mathrm{~W}_{x} \mathrm{~S}_{2}$ multilayer using a sequential super-cycle ALD process-specifically, 5 continuous super-cycles of ALD with different cycle ratios for each supercycle. Ultraviolet-visible spectrophotometer analysis shows that the synthesized VCC $\mathrm{Mo}_{1-x} \mathrm{~W}_{x} \mathrm{~S}_{2}$ multilayer has stronger interlayer coupling than that of a stacked VCC $\mathrm{Mo}_{1-x} \mathrm{~W}_{x} \mathrm{~S}_{2}$ multilayer fabricated by the individual transfer of each monolayer $\mathrm{Mo}_{1-x} \mathrm{~W}_{x} \mathrm{~S}_{2}$ alloy. This can be attributed to the clean interface between each layer in the synthesized sample ${ }^{15,21}$.

\section{Results}

$\mathrm{MoS}_{2}$ synthesis. Previously, we reported the synthesis of $\mathrm{WS}_{2}$ using sulfurization of $\mathrm{ALD} \mathrm{WO}_{3}$ thin film with a one-step sulfurization process at $1,000^{\circ} \mathrm{C}$ (ref. 30). These synthesized $\mathrm{WS}_{2}$ exhibit smooth and continuous surfaces with layer controllability from mono- to tetra-layer. Based on this result, we sulfurized ALD $\mathrm{MoO}_{x}$ thin film (nine cycles, optimization of ALD $\mathrm{MoO}_{x}$ is represented in Supplementary Fig. 1) using a one-step sulfurization process at $1,000^{\circ} \mathrm{C}$ (see experimental section) to synthesize $\mathrm{MoS}_{2}$. Figure 1a,b comprises scanning electron microscope (SEM) and atomic force microscopy (AFM) images of sulfurized $\mathrm{MoO}_{x}$ thin film using the one-step sulfurization
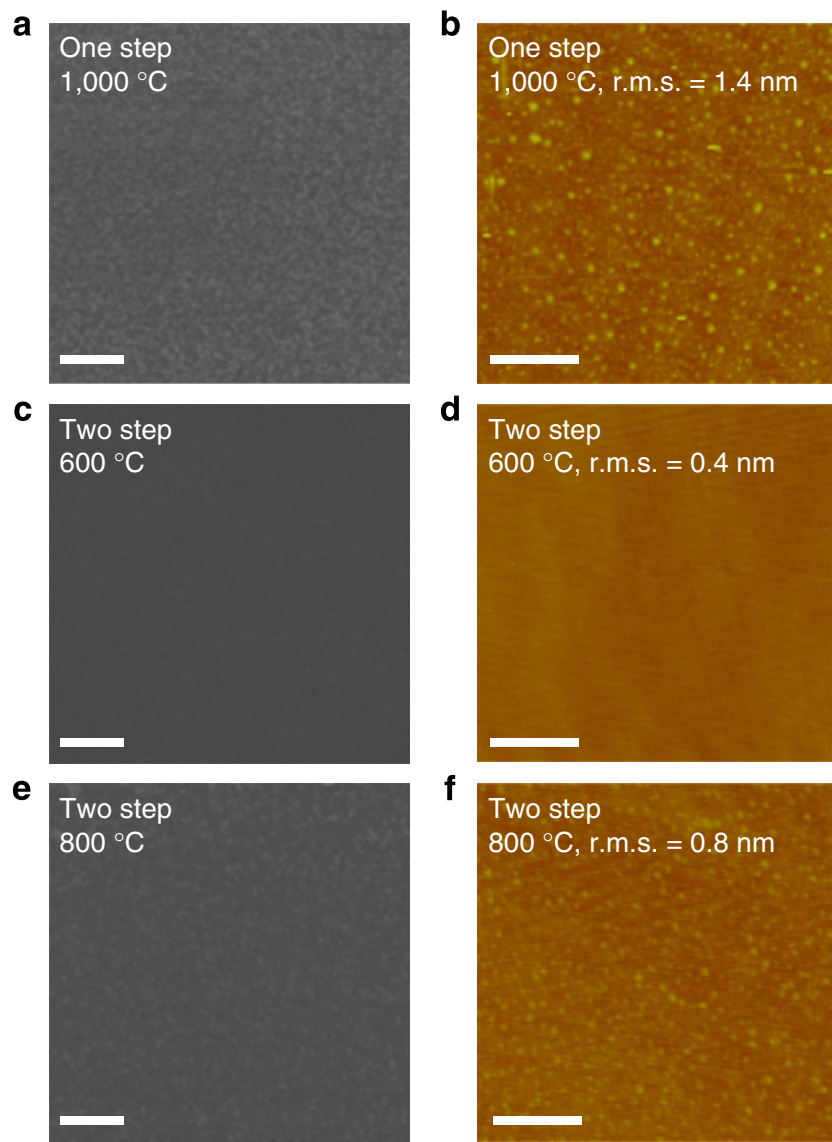

Figure 1 | Sulfurization of $\mathbf{M o O}_{\boldsymbol{x}}$ thin films. (a) SEM and (b) AFM images of sulfurized $\mathrm{MoO}_{x}$ thin film using one-step sulfurization process at $1,000^{\circ} \mathrm{C}$. SEM and AFM images of sulfurized $\mathrm{MoO}_{x}$ thin film using two-step sulfurization process with first-sulfurization temperatures of (c,d) 600 and $(\mathbf{e , f}) 800^{\circ} \mathrm{C}$, respectively. Scale bars, $(\mathbf{a}, \mathbf{c}, \mathbf{e}) 200 \mathrm{~nm}$ and $(\mathbf{b}, \mathbf{d}, \mathbf{f}) 0.5 \mu \mathrm{m}$.

process at $1,000^{\circ} \mathrm{C}$. In contrast to $\mathrm{WS}_{2}$, however, the $\mathrm{MoS}_{2}$ shows a rough and non-continuous surface, and the measured root mean square (r.m.s.) is much larger $(1.4 \mathrm{~nm})$ than that of the $\mathrm{SiO}_{2}$ substrate $(0.37 \mathrm{~nm})$. We surmise that this discrepancy between the $\mathrm{MoO}_{x}$ and $\mathrm{WO}_{3}$ thin films sulfurized at the same temperature $\left(1,000^{\circ} \mathrm{C}\right)$ is caused by the relatively lower vaporization temperature of $\mathrm{MoO}_{x}\left(\sim 700^{\circ} \mathrm{C}\right)$ in comparison with $\mathrm{WO}_{3}$ (over $\left.1,100^{\circ} \mathrm{C}\right)^{31}$. In other words, the $\mathrm{MoO}_{x}$ is vaporized before the conversion to $\mathrm{MoS}_{2}$ is complete, resulting in a rough surface.

Therefore, we examined the effect of sulfurization temperature on the roughness of the sulfurized ALD $\mathrm{MoO}_{x}$ thin film. To achieve this, we conducted a two-step sulfurization process, which consists of a low-temperature first step for the sulfurization of the $\mathrm{MoO}_{x}$ and a high-temperature second step to enhance the $\mathrm{MoS}_{2}$ crystallinity. The first-sulfurization temperatures were set to lower $\left(600^{\circ} \mathrm{C}\right)$ and higher $\left(800^{\circ} \mathrm{C}\right)$ temperatures than the vaporization temperature of $\mathrm{MoO}_{x}\left(700^{\circ} \mathrm{C}\right)$, while the secondsulfurization temperature and process time were kept at $1,000^{\circ} \mathrm{C}$ and $150 \mathrm{~min}$, respectively (see Methods section). The roughness of the sulfurized $\mathrm{MoO}_{x}$ thin films in accordance with firstsulfurization temperature was then compared using SEM and AFM (Fig. 1c-f). Figure 1c,e shows SEM images of the sulfurized $\mathrm{MoO}_{x}$ thin films for first-sulfurization temperatures of $600^{\circ} \mathrm{C}$ and $800^{\circ} \mathrm{C}$, respectively. The sulfurized $\mathrm{MoO}_{x}$ thin film at a first-sulfurization temperature of $600^{\circ} \mathrm{C}$ has a smooth and continuous surface, while the $\mathrm{MoO}_{x}$ thin film sulfurized at a first-sulfurization temperature of $800^{\circ} \mathrm{C}$ has a rough and 
non-continuous surface. AFM analyses (Fig. 1d,f) illustrate the variations in the roughness of the sulfurized $\mathrm{MoO}_{x}$ thin films more clearly, which is due to the differing first-sulfurization temperatures. The r.m.s. value for the $\mathrm{MoS}_{2}$ sulfurized at $600^{\circ} \mathrm{C}$ is very low $(\sim 0.4 \mathrm{~nm})$ and is close to the r.m.s. value of the $\mathrm{SiO}_{2}$ substrate $(0.37 \mathrm{~nm})$. In contrast, the r.m.s. value of the $\mathrm{MoS}_{2}$ in the $800{ }^{\circ} \mathrm{C}$ case is relatively high $(0.8 \mathrm{~nm})$. As a result, a firstsulfurization temperature of $600{ }^{\circ} \mathrm{C}$ results in $\mathrm{MoS}_{2}$ with uniform and continuous surfaces, due to the fact that the first-sulfurization temperature is lower than the vaporization temperature of $\mathrm{MoO}_{x}$, as we assumed. Based on this result, we used a two-step sulfurization process with a $600^{\circ} \mathrm{C}$ first-sulfurization temperature to synthesize continuous $\mathrm{MoS}_{2}$ and $\mathrm{Mo}_{1-x} \mathrm{~W}_{x} \mathrm{~S}_{2}$ alloys.

Next, layer-number-controlled $\mathrm{MoS}_{2}$ was synthesized utilizing the two-step sulfurization process described above. Figure $2 \mathrm{a}-\mathrm{d}$ shows the AFM images and height profiles of the transferred $\mathrm{MoS}_{2}$, which were synthesized by sulfurizing $\mathrm{MoO}_{x}$ thin films deposited by 6,9 and 12 ALD cycles. The measured thicknesses of the synthesized $\mathrm{MoS}_{2}$ were $\sim 1,1.6$ and $2.3 \mathrm{~nm}$ for 6,9 and 12 $\mathrm{MoO}_{x}$ ALD cycles, respectively. These thicknesses correspond to mono-, bi- and tri-layer (1,2 and 3l) $\mathrm{MoS}_{2}$, considering that the height of $11 \mathrm{MoS}_{2}$ on $\mathrm{SiO}_{2}$ is $\sim 1 \mathrm{~nm}$ and the spacing between the first and second $\mathrm{MoS}_{2}$ layers is $\sim 0.6 \mathrm{~nm}$ (refs 3,4). As reported previously, the larger AFM-measured spacing between the first $\mathrm{MoS}_{2}$ layer and the substrate, compared with that between the $\mathrm{MoS}_{2}$ layers, is caused by the effect of distinct tip-sample and tip-substrate interactions $s^{3,30,32}$. Also, the apparent colour gains of the transferred 1, 2 and $31 \mathrm{MoS}_{2}$ are observed in optical microscopy (OM) images (Supplementary Fig. 2). It should be noted that the $\mathrm{MoS}_{2}$ is not formed in the case of an ALD $\mathrm{MoO}_{x}$ thin film with an ALD cycle number of $<3$ (Supplementary Fig. 3). This is attributed to a nucleation delay during the initial growth of the $\mathrm{MoO}_{x}$, and similar behaviour was observed during the synthesis of $\mathrm{WS}_{2}$ by sulfurization of $\mathrm{ALD} \mathrm{WO}_{3}$ (ref. 30). After the nucleation delay, 11 of $\mathrm{MoS}_{2}$ is formed by the sulfurization of each three-cycle ALD $\mathrm{MoO}_{x}$ thin film sample $(\sim 0.8-0.9 \mathrm{~nm}$ in thickness). This observation agrees with a previous report, where $\sim 1 \mathrm{~nm}$ of $\mathrm{MoO}_{x}$ film transformed into a $11 \mathrm{MoS}_{2}$ via sulfurization $^{33}$. The stoichiometry calculated from X-ray photoemission spectroscopy (XPS) result is 2 (S/Mo) as shown in Supplementary Fig. 4. As a result, we can systematically control the layer number of $\mathrm{MoS}_{2}$ by controlling the ALD $\mathrm{MoO}_{x}$ cycle number.

The $\mathrm{MoS}_{2}$ were further characterized using Raman, PL and high-resolution TEM (HRTEM). The Raman spectra $\left(\lambda_{\text {exc }}=532 \mathrm{~nm}\right)$ for 1,21 and $31 \mathrm{MoS}_{2}$ are shown in Fig. 2e. The $\mathrm{MoS}_{2}$ exhibit in-plane and out-of-plane vibrations modes at 386.6 and $406.5 \mathrm{~cm}^{-1}\left(\mathrm{E}^{\prime}\right.$ and $\mathrm{A}_{1}^{\prime}$ ) for the $11,385.6$ and $407.6 \mathrm{~cm}^{-1}$ $\left(\mathrm{E}_{\mathrm{g}}^{1}\right.$ and $\mathrm{A}_{1 \mathrm{~g}}$ ) for $2 \mathrm{l}$, and 384.7 and $408.5 \mathrm{~cm}^{-1}\left(\mathrm{E}^{\prime 1}\right.$ and $\left.\mathrm{A}^{\prime}{ }_{1}\right)$ for 31 (ref. 34). From the Raman spectra, we calculated the relative peak distance between the in-plane and out-of-plane modes, which is closely related to the layer number of the $\mathrm{MoS}_{2}$ due to the softening in the in-plane and stiffening in the out-of-plane mode frequencies, with increasing layer numbers ${ }^{35,36}$. The calculated relative peak distances are $19.9,22$ and $23.8 \mathrm{~cm}^{-1}$ for the 1,2 and 31 samples, respectively, which are in good agreement with previously reported values for synthesized $\mathrm{MoS}_{2}$ (refs 37-39).

The PL spectra dependence on the layer number of the $\mathrm{MoS}_{2}$ is shown in Fig. 2f. The spectrum of the $11 \mathrm{MoS}_{2}$ shows PL peaks at $1.89 \mathrm{eV}$ and $2.01 \mathrm{eV}$, which are correlated to the $A_{1}$ and $B_{1}$ direct excitonic transitions of the $\mathrm{MoS}_{2}$, respectively. With increasing layer number, weak PL peaks are observed at $1.87 \mathrm{eV}$ and $2.00 \mathrm{eV}$ for the 21 , and $1.86 \mathrm{eV}$ and $1.99 \mathrm{eV}$ for the 31 . The red shift and low intensity of the PL peaks with increasing layer number is due to the band gap transition from direct to indirect, which is consistent with the dependency of the PL peak on the layer number ${ }^{4-6,40}$. These Raman and PL results again confirm the layer controllability of $\mathrm{MoS}_{2}$ using the ALD process. Figure $2 \mathrm{~g}$ is an HRTEM image for the synthesized $11 \mathrm{MoS}_{2}$. The $\mathrm{MoS}_{2}$ shows a honeycomb-like structure with lattice spacing of $0.27 \mathrm{~nm}$ and $0.16 \mathrm{~nm}$ for the (100) and (110) planes, respectively. In addition, sixfold coordination symmetry is observed in the fast Fourier transformation (FFT) image (inset of Fig. 2g). The approximate
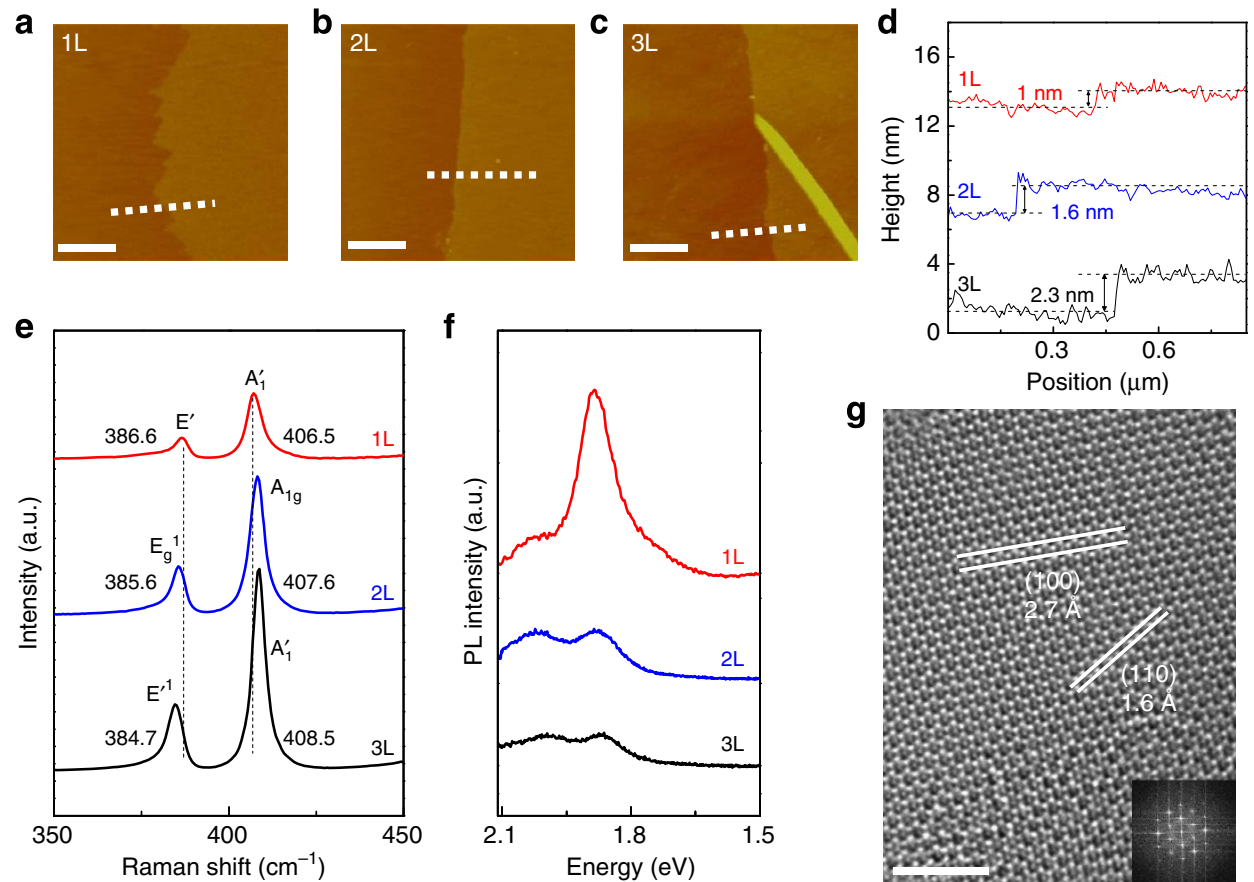

Figure 2 | Characterization of $\mathbf{M o S}_{\mathbf{2}}$. (a-c) AFM images and (d) height profiles (along with white dashed line in AFM images) of transferred MoS 2 on $\mathrm{SiO}_{2}$ substrate for $1 \mathrm{l}, 2 \mathrm{l}$ and $3 \mathrm{l}$ thickness, respectively. Scale bars, $0.5 \mu \mathrm{m}$. (e) Raman spectra and (f) PL spectra for $1 \mathrm{l}$ (red), $2 \mathrm{l}$ (blue) and $3 \mathrm{l}$ (black) $\mathrm{MoS}_{2}$ on $\mathrm{SiO}_{2}$ substrate. (g) HRTEM image of $11 \mathrm{MoS}_{2}$ at a selected region and (inset) FFT pattern. Scale bars, $2 \mathrm{~nm}$. 
domain size is $10-20 \mathrm{~nm}$, similar to that of previously reported synthesized $\mathrm{MoS}_{2}$ and $\mathrm{WS}_{2}$ using the sulfurization of $\mathrm{MoO}_{x}$ and $\mathrm{WO}_{3}$ thin films ${ }^{30,41}$.

$\mathbf{M o}_{1-x} \mathbf{W}_{x} \mathbf{S}_{2}$ alloy synthesis. A super-cycle ALD-based $\mathrm{Mo}_{1-x} \mathrm{~W}_{x} \mathrm{~S}_{2}$ alloy synthesis process was developed based on the synthesis processes for $2 \mathrm{D} \mathrm{MoS}_{2}$ (this study) and $\mathrm{WS}_{2}$ (previous study $)^{30}$. The overall synthesis scheme for the $\mathrm{Mo}_{1-x} \mathrm{~W}_{x} \mathrm{~S}_{2}$ alloy is illustrated in Fig. 3a. First, we conducted 10 cycles of $\mathrm{WO}_{3}$ ALD to address the nucleation delay of the ALD $\mathrm{WO}_{3}$ (ref. 30) (not shown in Fig. 3a). Subsequently, one super-cycle ALD process consisting of $n$ cycles of ALD $\mathrm{MoO}_{x}$ and $m$ cycles of ALD $\mathrm{WO}_{3}$ was conducted and the deposited $\mathrm{Mo}_{1-x} \mathrm{~W}_{x} \mathrm{O}_{y}$ alloy thin films were sulfurized. We used varying cycles for $\mathrm{MoO}_{x}(n)$ and $\mathrm{WO}_{3}(m)$ in one super-cycle to deposit $0.8-0.9-\mathrm{nm}$-thick composition-controlled $\mathrm{Mo}_{1-x} \mathrm{~W}_{x} \mathrm{O}_{y}$ alloy thin films to create a $11 \mathrm{Mo}_{1-x} \mathrm{~W}_{x} \mathrm{~S}_{2}$ alloy. This was based on the growth rate of ALD $\mathrm{MoO}_{x}(2.7 \AA$ per cycle $)$ and $\mathrm{WO}_{3}(0.9 \AA$ per cycle $)$, as shown in Supplementary Table 1 . Figure $3 \mathrm{~b}-\mathrm{d}$ shows the XPS spectra of the $11 \mathrm{MoS}_{2}, 11 \mathrm{WS}_{2}$ and sulfurized $\mathrm{Mo}_{1-x} \mathrm{~W}_{x} \mathrm{O}_{y}$ alloy thin films with different $n$ and $m$ numbers in one super-cycle. All measured XPS results were normalized by $S 2 \mathrm{p}_{3 / 2}$ peak intensity and calibrated to the $\mathrm{C} 1 \mathrm{~s}$ peak at $285 \mathrm{eV}$. With increasing $\mathrm{n} / \mathrm{m}$ ratio, the intensity of the Mo3d peaks increased, while the $\mathrm{W} 5 \mathrm{p}_{3 / 2}$ and $\mathrm{W} 4 \mathrm{f}$ peaks decreased. Furthermore, the peak positions for Mo3d and W4f gradually shifted to higher binding energies, from $232.2 \mathrm{eV}$ and $229.1 \mathrm{eV}$ to $232.5 \mathrm{eV}$ and $229.4 \mathrm{eV}$ for $\mathrm{Mo}_{3 / 2}$ and $\mathrm{Mo}_{5 / 2}$, respectively, and from $34.8 \mathrm{eV}$ and $32.6 \mathrm{eV}$ to $35.0 \mathrm{eV}$ and $32.8 \mathrm{eV}$ for $\mathrm{W}_{4} \mathrm{f}_{5 / 2}$ and $\mathrm{W} 4 \mathrm{f}_{7 / 2}$, respectively. In addition, the $\mathrm{S} 2 \mathrm{p}$ peaks shifted to lower binding energies, from $163.5 \mathrm{eV}$ and $162.4 \mathrm{eV}$ to $163.3 \mathrm{eV}$ and $162.2 \mathrm{eV}$ for $\mathrm{S} 2 \mathrm{p}_{1 / 2}$ and $\mathrm{S} 2 \mathrm{p}_{3 / 2}$, respectively. This small shift in peak position is attributed to the enhanced electron attraction strength of $S$ and the reduced electron attraction strength of $\mathrm{W}$, following increased Mo content due to smaller electronegativity of Mo (2.16) than that of W (2.36) as previously reported $^{7}$. It is noteworthy that the $\mathrm{Mo}^{6+} 3 \mathrm{~d}_{3 / 2}$ peak, which is attributed to the Mo-O bonding, is not observed in the Mo3d spectra; this indicates the absence of $\mathrm{O}$ species.

We calculated the Mo, W and $\mathrm{S}$ concentrations from the XPS results for the Mo3d, W4f and S2p peaks, respectively, to examine the $\mathrm{Mo}_{1-{ }_{x}} \mathrm{~W}_{x} \mathrm{~S}_{2}$ alloy composition. Table 1 presents the calculated concentration and $\mathrm{W}$ composition, $x$. The calculated $x$ value is dependent on the $n$ and $m$ numbers in a single supercycle, and yields $x=0.8$ for $n=1$ and $m=6, x=0.6$ for $n=2$ and $m=4$, and $x=0.3$ for $n=3$ and $m=1$. Also, the calculated stoichiometry is $2(\mathrm{~S} /(\mathrm{Mo}+\mathrm{W}))$. This shows that the $\mathrm{W}$ composition $(x)$ in the $\mathrm{Mo}_{1-x} \mathrm{~W}_{x} \mathrm{~S}_{2}$ alloys can be systematically modulated by changing the values of $n$ and $m$ in one super-cycle.

The synthesized composition-controlled $\mathrm{Mo}_{1-x} \mathrm{~W}_{x} \mathrm{~S}_{2}$ alloy from super-cycle $\mathrm{ALD} \mathrm{Mo}_{1-x} \mathrm{~W}_{x} \mathrm{O}_{y}$ alloy thin films were characterized using AFM, Raman and PL, as shown in Fig. 4. The AFM images and height profiles of the transferred $\mathrm{Mo}_{1-x} \mathrm{~W}_{x} \mathrm{~S}_{2}$ alloys are represented in Fig. $4 \mathrm{a}-\mathrm{d}$ and they show good uniformity and continuity (also see OM images in a

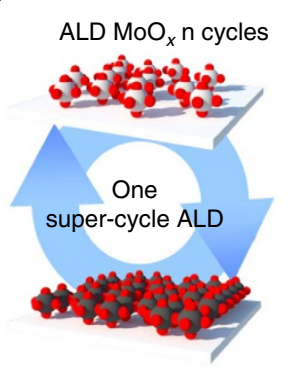

$\mathrm{ALD} \mathrm{WO}_{3} \mathrm{~m}$ cycles

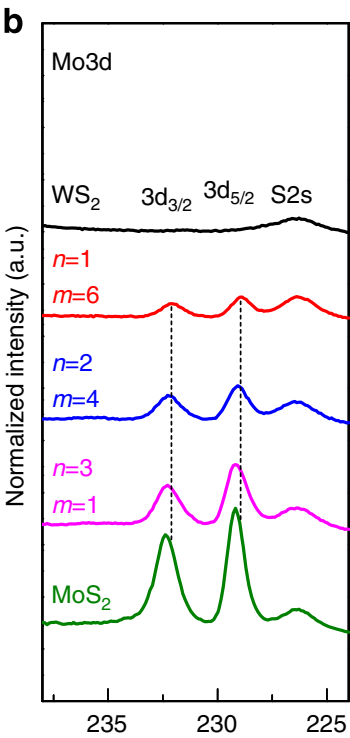

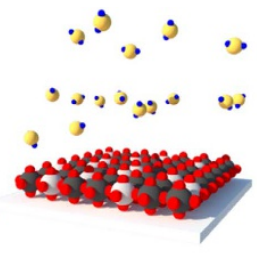

$\mathrm{Mo}_{1-x} \mathrm{~W}_{x} \mathrm{O}_{y}$

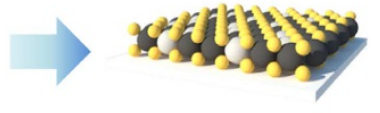

$\mathrm{Mo}_{1-x} \mathrm{~W}_{x} \mathrm{~S}_{2}$
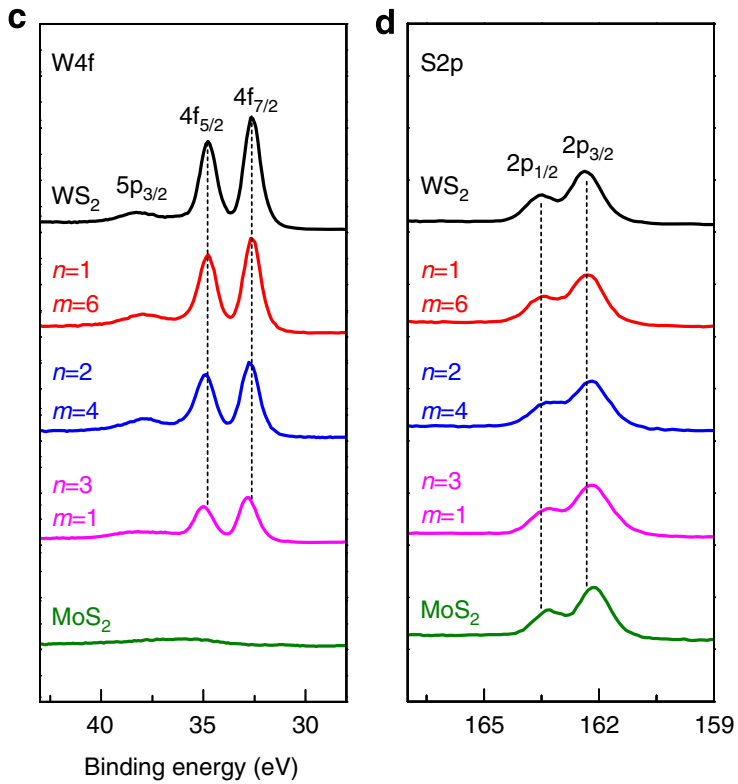

Figure 3 | Synthesis and XPS of $\mathbf{M o}_{\mathbf{1}_{-}} \mathbf{W}_{\mathbf{x}} \mathbf{S}_{\mathbf{2}}$ alloy. (a) Synthesis procedure of super-cycle ALD for $\mathrm{Mo}_{1-x} \mathrm{~W}_{x} \mathrm{~S}_{2}$ alloy. XPS measurements for (b) Mo3d, (c) W4f and (d) S2p core levels in the $11 \mathrm{Mo}_{1-x} \mathrm{~W}_{x} \mathrm{~S}_{2}$ alloy with different $n$ and $m$ numbers in one super-cycle. All measured XPS results are normalized by $\mathrm{S} 2 \mathrm{p}_{3 / 2}$ peak intensity. 
Supplementary Fig. 5). The measured thicknesses of the $\mathrm{Mo}_{0.2} \mathrm{~W}_{0.8} \mathrm{~S}_{2}, \quad \mathrm{Mo}_{0.4} \mathrm{~W}_{0.6} \mathrm{~S}_{2}$ and $\mathrm{Mo}_{0.7} \mathrm{~W}_{0.3} \mathrm{~S}_{2}$ alloys were all $\sim 1 \mathrm{~nm}$, corresponding to the 11 thickness of $\mathrm{Mo}_{1-x} \mathrm{~W}_{x} \mathrm{~S}_{2}$ alloy. Furthermore, 2 and $3 \mathrm{l} \mathrm{Mo}_{1-x} \mathrm{~W}_{x} \mathrm{~S}_{2}$ alloys can be synthesized using two- and three-super-cycle ALD $\mathrm{Mo}_{1-x} \mathrm{~W}_{x} \mathrm{O}_{y}$ alloy thin films (Supplementary Fig. 6). As a result, our super-cycle ALDbased $\mathrm{Mo}_{1-x} \mathrm{~W}_{x} \mathrm{~S}_{2}$ alloy synthesis process can systematically control the layer number, as well as the composition of the resultant alloys through manipulation of the super-cycle ALD process.

Figure 4e shows the Raman spectra of composition-controlled $11 \mathrm{Mo}_{1-x} \mathrm{~W}_{x} \mathrm{~S}_{2}$ alloys. The $11 \mathrm{WS}_{2}(x=1)$ exhibits first-order modes: out-of-plane $\left(\mathrm{A}^{\prime}{ }_{1}\right)$ and in-plane $\left(\mathrm{E}^{\prime}\right)$ modes at $417 \mathrm{~cm}^{-1}$ and $357 \mathrm{~cm}^{-1}$, respectively, and a second-order mode: $2 \mathrm{LA}(\mathrm{M})$ at $353 \mathrm{~cm}^{-1}$ (ref. 30). The $\mathrm{A}^{\prime}{ }_{1}$ mode shifts to a lower frequency with decreasing $\mathrm{W}$ composition, while the $\mathrm{E}^{\prime}$ mode related to $\mathrm{WS}_{2}$ does not noticeably shift with the reduction of intensity. In addition, an $\mathrm{E}^{\prime}$ mode related to $\mathrm{MoS}_{2}$ appear at $x=0.8$ and shifted to a higher frequency with a reduction in $\mathrm{W}$ composition. The specific peak position dependency on $\mathrm{W}$ composition is represented in Supplementary Fig. 7, and the W composition

\begin{tabular}{|c|c|c|c|c|c|}
\hline \multicolumn{2}{|c|}{ One super-cycle } & \multirow[t]{2}{*}{ Mo (\%) } & \multirow[t]{2}{*}{ W (\%) } & \multirow[t]{2}{*}{ S (\%) } & \multirow[t]{2}{*}{ W composition $x$} \\
\hline$\underline{n}$ & $\boldsymbol{m}$ & & & & \\
\hline 1 & 6 & 6.9 & 26.5 & 66.6 & 0.8 \\
\hline 2 & 4 & 12.5 & 19.3 & 68.2 & 0.6 \\
\hline 3 & 1 & 22.5 & 10.5 & 67 & 0.3 \\
\hline
\end{tabular}

Quantification analysis for Mo3d, W4f and S2p peaks depending on $n$ and $m$ number in one super-cycle. The calculation error for the composition is under $1 \%$. dependence of the Raman spectra of the $11 \mathrm{Mo}_{1-x} \mathrm{~W}_{x} \mathrm{~S}_{2}$ alloy is consistent with previous reports ${ }^{7-9}$.

The normalized PL spectra of the composition-controlled 11 $\mathrm{Mo}_{1-x} \mathrm{~W}_{x} \mathrm{~S}_{2}$ alloys are shown in Fig. $4 \mathrm{f}$, also the $x$ values versus the average PL peak positions and s.d. of five-times repeatedly synthesized $11 \mathrm{Mo}_{1-x} \mathrm{~W}_{x} \mathrm{~S}_{2}$ alloys are plotted in Fig. $4 \mathrm{~g}$. As the value of $x$ increased from 0 to 1 , the averaged PL peak position initially decreases from 1.885 to $1.863 \mathrm{eV}$, and then gradually increases to $2.021 \mathrm{eV}$. This non-linear PL peak position behaviour with changing $x$ is the so-called 'bowing effect', and has also been reported for other semiconducting alloys and exfoliated 11 $\mathrm{Mo}_{1-x} \mathrm{~W}_{x} \mathrm{~S}_{2}$ alloys $9,42,43$. The bowing effect in $11 \mathrm{Mo}_{1-x} \mathrm{~W}_{x} \mathrm{~S}_{2}$ alloy can be described by the Equation (1),

$$
\mathrm{E}_{\mathrm{PL}, \mathrm{Mo}_{(1-x)} \mathrm{W}_{x} \mathrm{~S}_{2}}=(1-x) \mathrm{E}_{\mathrm{PL}, \mathrm{MoS}_{2}}+x \mathrm{E}_{\mathrm{PL}, \mathrm{WS}_{2}}-b x(1-x),
$$

where $b$ is a bowing parameter. After fitting the experimental results as shown in Fig. $4 \mathrm{~g}$ (red solid curve), a $b$ value of $0.25 \pm 0.03 \mathrm{eV}$ was extracted. The extracted $b$ value is comparable to that of the previous experiment $(0.25 \pm 0.04 \mathrm{eV})$ and simulation $(0.28 \pm 0.04 \mathrm{eV})$ results 9 . Furthermore, the s.d. of the five-times repeatedly synthesized $11 \mathrm{Mo}_{1-x} \mathrm{~W}_{x} \mathrm{~S}_{2}$ alloys are small within the range of 0.008 to 0.01 , which indicates that the process has good reliability in terms of composition control. Thus, the PL result confirms that we modulate the band gap of the $\mathrm{Mo}_{1-x} \mathrm{~W}_{x} \mathrm{~S}_{2}$ alloy by reliably controlling the composition. Moreover, the band gap can also be modulated by controlling the layer number (see Supplementary Fig. 8).

Figure $5 \mathrm{a}$ is the HRTEM image of the $11 \mathrm{Mo}_{0.4} \mathrm{~W}_{0.6} \mathrm{~S}_{2}$ alloy $(x=0.6)$. The $\mathrm{Mo}_{0.4} \mathrm{~W}_{0.6} \mathrm{~S}_{2}$ alloy shows a periodic atomic arrangement with a honeycomb-like structure and sixfold coordination symmetry, similar to the $11 \mathrm{MoS}_{2}$ shown in Fig. 2f. To distinguish between the $\mathrm{W}$ and Mo atoms in the 11 $\mathrm{Mo}_{0.4} \mathrm{~W}_{0.6} \mathrm{~S}_{2}$ alloy, we analysed the $\mathrm{Mo}_{0.4} \mathrm{~W}_{0.6} \mathrm{~S}_{2}$ alloy using STEM
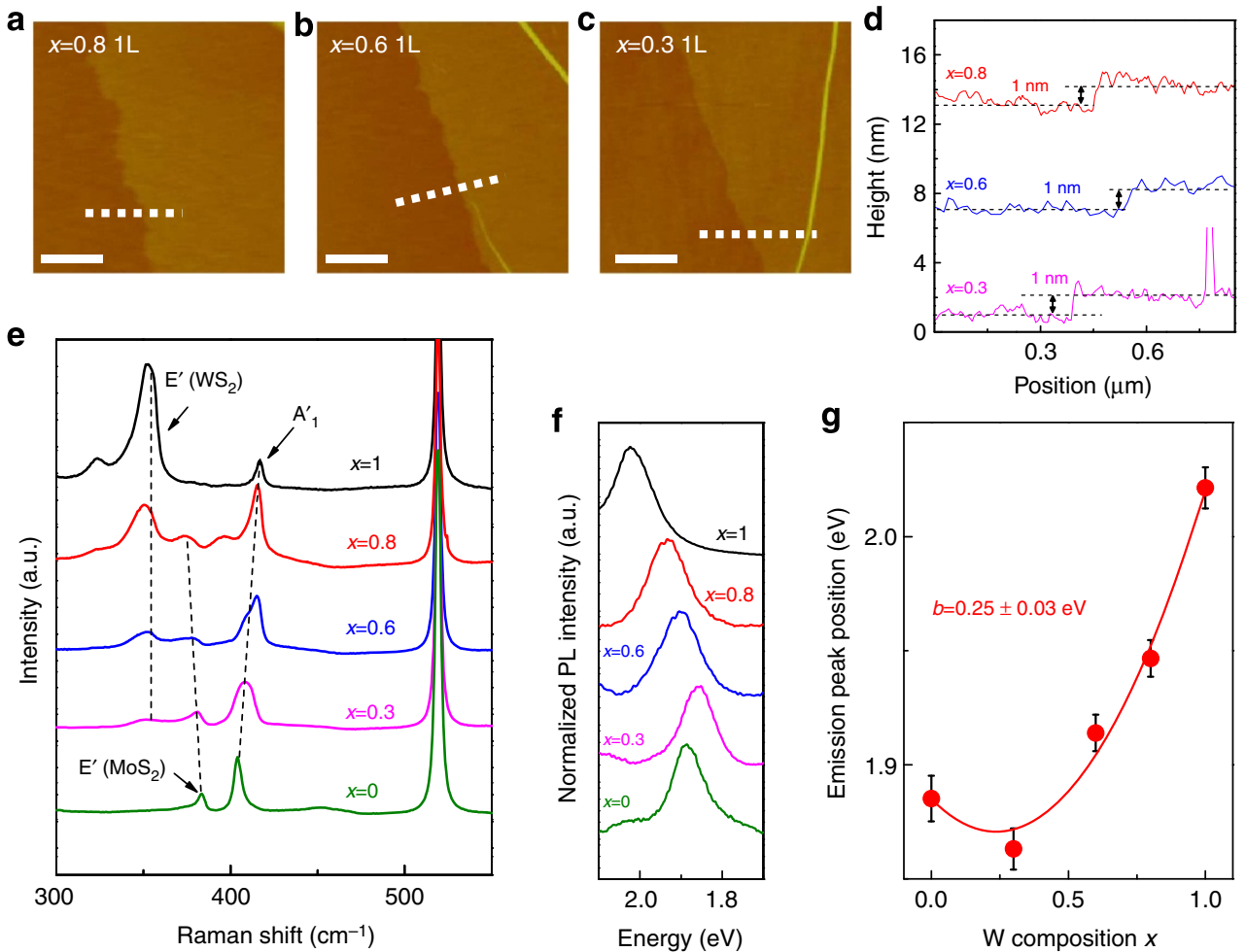

Figure 4 | Characterization of $\mathbf{M o}_{\mathbf{1}_{-\mathbf{x}}} \mathbf{W}_{\mathbf{x}} \mathbf{S}_{\mathbf{2}}$ alloy. (a-c) AFM images and (d) height profiles (along with white dashed line in AFM images) of transferred 11 $\mathrm{Mo}_{1-x} \mathrm{~W}_{x} \mathrm{~S}_{2}$ alloy on $\mathrm{SiO}_{2}$ substrate for $x=0.8,0.6$ and 0.3 , respectively. Scale bars, $0.5 \mu \mathrm{m}$. (e) Raman spectra and (f) PL spectra for $11 \mathrm{Mo}_{1-x} \mathrm{~W}_{x} \mathrm{~S}_{2}$ alloy on $\mathrm{SiO}_{2}$ substrate for $x=1,0.8,0.6,0.3$ and $\mathrm{O}$. $(\mathbf{g}) \mathrm{PL}$ peak position versus $\mathrm{W}$ composition $(x)$ graph. Error bars represent s.d. of PL peak position in five-times repeatedly synthesized $\mathrm{Mo}_{1-x} \mathrm{~W}_{x} \mathrm{~S}_{2}$ alloy. 
annular dark-field and energy dispersive X-ray spectrometry (EDX). Figure $5 \mathrm{~b}$ is the STEM-ADF image of the $11 \mathrm{Mo}_{0.4} \mathrm{~W}_{0.6} \mathrm{~S}_{2}$ alloy. Brighter and less bright spots, which correspond to $\mathrm{W}$ and Mo atoms, respectively, are clearly resolved in the ADF image, as previously reported ${ }^{44}$. The calculated $\mathrm{Mo} / \mathrm{W}$ ratio from the atom count in Fig. $5 b$ is $0.42: 0.58$, which differs by $<5 \%$ from the XPS-measured stoichiometry. In addition, the EDX result in Fig. $5 \mathrm{c}$ supports the presence of $\mathrm{W}, \mathrm{Mo}$ and $\mathrm{S}$ species in the 11 $\mathrm{Mo}_{0.4} \mathrm{~W}_{0.6} \mathrm{~S}_{2}$ alloy. To extract a clear intensity difference between the $\mathrm{W}$ and Mo atoms, we performed an inverse FFT by applying a mask to the yellow dashed square region in Fig. 5b. Figure $5 \mathrm{~d}-\mathrm{e}$ shows the inversed FFT image (Fig. 5d) and intensity profile (Fig. 5e) along with the yellow solid line in Fig. 5d. Although S atoms are not distinguishable in our result as a result of the displacement of $\mathrm{S}$ atoms at $200 \mathrm{kV}$ operation voltage by the knock-on mechanism ${ }^{45}$, the $\mathrm{W}$ and Mo atoms are clearly observable, confirming that these elements share the metal atom sites ${ }^{44}$. The preference for Mo or $\mathrm{W}$ atoms at the neighbouring sites of $\mathrm{W}$ atoms is evaluated by degree of alloying that can be calculated by Equation $(2)^{23,44}$,

$$
J_{\mathrm{W}}=P_{\text {observed }} / P_{\text {random }} \times 100 \%,
$$

where $P_{\text {observed }}$ is the averaged ratio of number of neighbouring Mo atoms to total neighbouring sites of $\mathrm{W}$ atoms, and $P_{\text {random }}$ is the total ratio of Mo atoms in the examined layer. Figure $5 \mathrm{f}$ represented differently coloured $\mathrm{W}$ atoms depending on number of neighbouring Mo atoms: light brown, blue, red, dark red, yellow, green and violet for six, five, four, three, two, one and zero number of neighbouring Mo atoms. The calculated degree of alloying is $99 \%$, which indicate that there is no preference for Mo or $\mathrm{W}$ atoms at the neighbouring sites of $\mathrm{W}$ atoms and a random mixture of our $11 \mathrm{Mo}_{1-x} \mathrm{~W}_{x} \mathrm{~S}_{2}$ alloy.

A VCC $\mathbf{M o}_{1-x} \mathbf{W}_{x} \mathbf{S}_{2}$ synthesis. The composition controllability of our ALD-based $\mathrm{Mo}_{1-x} \mathrm{~W}_{x} \mathrm{~S}_{2}$ alloy synthesis process enables synthesis of a VCC $\mathrm{Mo}_{1-x} \mathrm{~W}_{x} \mathrm{~S}_{2}$ multilayer with a clean interface, strong interlayer coupling and broadband light absorption. We sulfurized a VCC $\mathrm{Mo}_{1-x} \mathrm{~W}_{x} \mathrm{O}_{y}$ thin film that was deposited by a sequential super-cycle ALD process, so as to synthesize a VCC $\mathrm{Mo}_{1-x} \mathrm{~W}_{x} \mathrm{~S}_{2}$ multilayer, as shown in Fig. 6a. First, we conducted 20 cycles of $\mathrm{WO}_{3} \mathrm{ALD}$ on a $\mathrm{SiO}_{2}$ substrate, corresponding to $11 \mathrm{WS}_{2}$. We immediately performed three super-cycles of
$\mathrm{Mo}_{1-x} \mathrm{~W}_{x} \mathrm{O}_{y}$ ALD with different super-cycle $n$ and $m$ numbers, in the following order: $n=1$ and $m=6, n=2$ and $m=4$, and $n=3$ and $m=1$. Last, we conducted three cycles of $\mathrm{MoO}_{x}$ $\operatorname{ALD}(n=3)$ corresponding to $11 \mathrm{MoS}_{2}$. The deposited VCC $\mathrm{Mo}_{1-x} \mathrm{~W}_{x} \mathrm{O}_{y}$ thin film was sulfurized to convert it into a VCC $\mathrm{Mo}_{1-x} \mathrm{~W}_{x} \mathrm{~S}_{2}$ multilayer. Figure 6b,c shows an AFM image and height profile of the transferred VCC $\mathrm{Mo}_{1-x} \mathrm{~W}_{x} \mathrm{~S}_{2}$ multilayer, with a measured thickness of $\sim 3.5 \mathrm{~nm}$. This thickness, synthesized by five sequential ALD super-cycles, corresponds to a $5 \mathrm{Mo}_{1-x} \mathrm{~W}_{x} \mathrm{~S}_{2}$ alloy, which is consistent with each super-cycle result for the $11 \mathrm{Mo}_{1-x} \mathrm{~W}_{x} \mathrm{~S}_{2}$ alloy.

The different composition concentrations of the bottom and top layers in the VCC $\mathrm{Mo}_{1-x} \mathrm{~W}_{x} \mathrm{~S}_{2}$ multilayer were analysed using angle-resolved XPS (ARXPS). Figure 6d shows the calculated atomic and relative concentration ratios of the Mo and $\mathrm{W}$ from the ARXPS measurement (ARXPS spectra are shown in Supplementary Fig. 9). The Mo concentration increased from 18.6 to $20.9 \%$, while the $\mathrm{W}$ concentration decreased from 15.7 to $13.5 \%$, with increasing emission angle from 0 to $70^{\circ}$ (red line). The Mo/W concentration ratio increased from 1.17 to 1.55 with increasing emission angle (blue line). Although the exact atomic concentration according to position in the VCC $\mathrm{Mo}_{1-x} \mathrm{~W}_{x} \mathrm{~S}_{2}$ multilayer cannot be calculated because of the larger depth resolution of the XPS measurement in comparison with the VCC $\mathrm{Mo}_{1-x} \mathrm{~W}_{x} \mathrm{~S}_{2}$ multilayer thickness, the emission angle dependency of the Mo and $\mathrm{W}$ concentration indicates Mo-rich and $\mathrm{W}$-rich concentration in the upper and lower layers of the VCC $\mathrm{Mo}_{1-x} \mathrm{~W}_{x} \mathrm{~S}_{2}$ multilayer, respectively. As a result, ARXPS shows that the VCC $\mathrm{Mo}_{1-x} \mathrm{~W}_{x} \mathrm{~S}_{2}$ multilayer has VCC characteristics. Notably, the calculated stoichiometry ratio was $2(\mathrm{~S} /(\mathrm{Mo}+\mathrm{W}))$ in all ARXPS results.

The formation of $\mathrm{Mo}_{1-x} \mathrm{~W}_{x} \mathrm{~S}_{2}$ alloy with different compositions in a VCC $\mathrm{Mo}_{1-x} \mathrm{~W}_{x} \mathrm{~S}_{2}$ multilayer was analysed using Raman spectroscopy. Figure 6e shows the Raman spectrum of a VCC $\mathrm{Mo}_{1-x} \mathrm{~W}_{x} \mathrm{~S}_{2}$ multilayer, which exhibits strong peaks for $\mathrm{A}_{1 \mathrm{~g}}, \mathrm{MoS}_{2}$-like $\mathrm{E}_{2 \mathrm{~g}}{ }_{2}$ and $\mathrm{WS}_{2}$-like $\mathrm{E}_{2 \mathrm{~g}}^{1}+2 \mathrm{LA}(\mathrm{M})$ modes. Each Raman peak can be fitted using a Lorentzian function to the Raman spectrum of the $\mathrm{Mo}_{1-x} \mathrm{~W}_{x} \mathrm{~S}_{2}$ alloy with $x=0,0.3,0.6$, 0.8 and 1. The fitted Raman spectrum was compared with the measured Raman spectrum for the $11 \mathrm{Mo}_{1-x} \mathrm{~W}_{x} \mathrm{~S}_{2}$ alloy, with respect to variations in the peak position and peak distances of the $\mathrm{A}_{1 \mathrm{~g}}$ and $\mathrm{MoS}_{2}$-like $\mathrm{E}_{2 \mathrm{~g}}^{1}$ modes, depending on
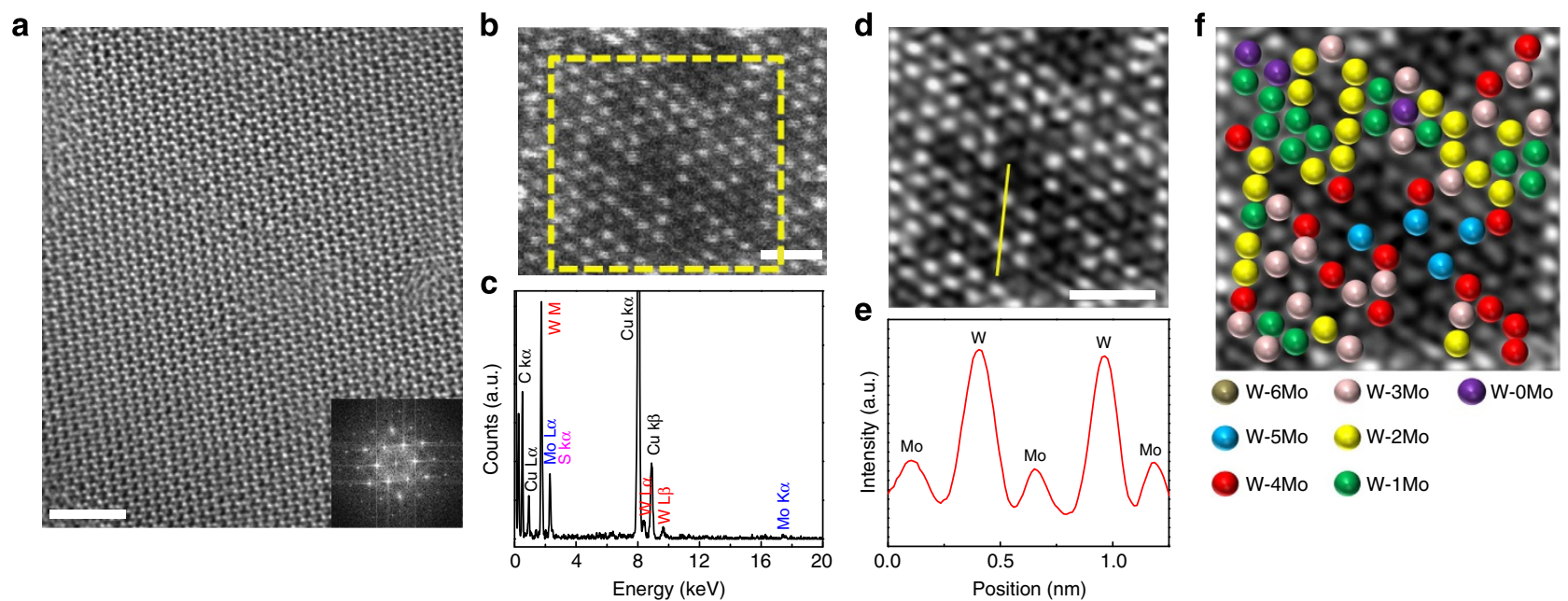

Figure 5 | Atomic arrangement and mixture of $\mathbf{M o}_{\mathbf{0 . 4}} \mathbf{W}_{\mathbf{0 . 6}} \mathbf{S}_{\mathbf{2}}$ alloy. (a) HRTEM image of $11 \mathrm{Mo}_{0.4} \mathrm{~W}_{0.6} \mathrm{~S}_{2}$ alloy at a selected region, and (inset) FFT pattern. Scale bars, $2 \mathrm{~nm}$. (b) STEM-ADF image of $11 \mathrm{Mo}_{0.4} \mathrm{~W}_{0.6} \mathrm{~S}_{2}$ alloy at a selected region and (c) corresponding EDX spectrum. Scale bars, $1 \mathrm{~nm}$. (d) Inverse FFT image with masking applied to yellow dashed square region in $\mathbf{b}$. Scale bars, $1 \mathrm{~nm}$. (e) Intensity profile of yellow solid line in d. (f) Coloured W atoms with light brown, blue, red, dark red, yellow, green and violet for six, five, four, three, two, one and zero number of neighbouring Mo atoms. 
a

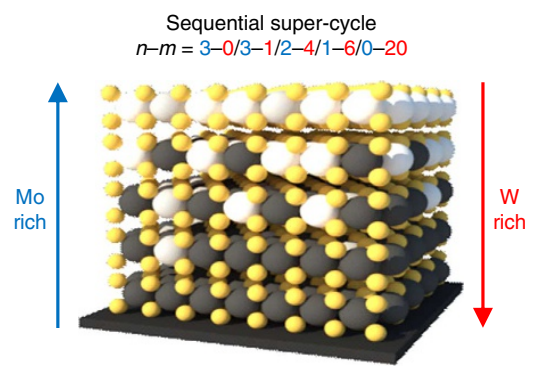

e

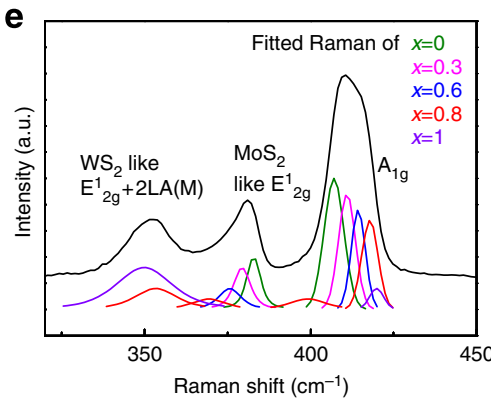

b

C
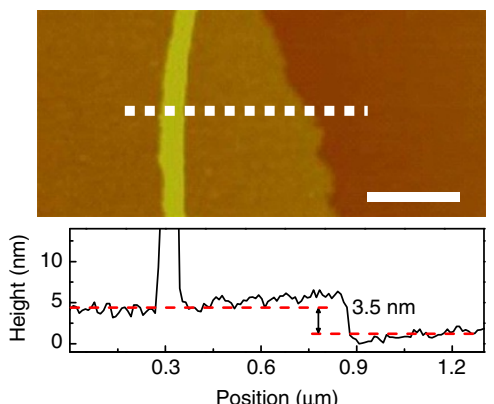

f

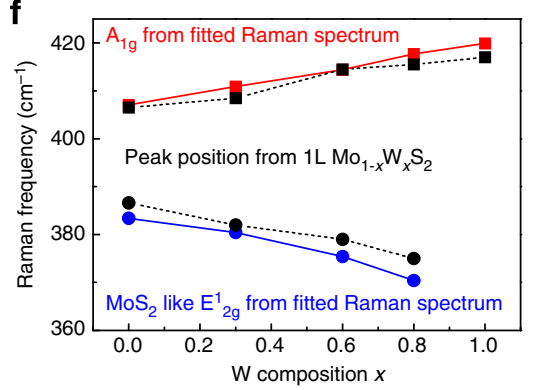

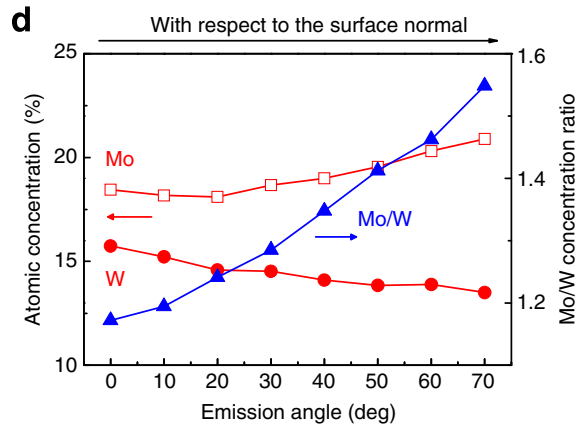

g

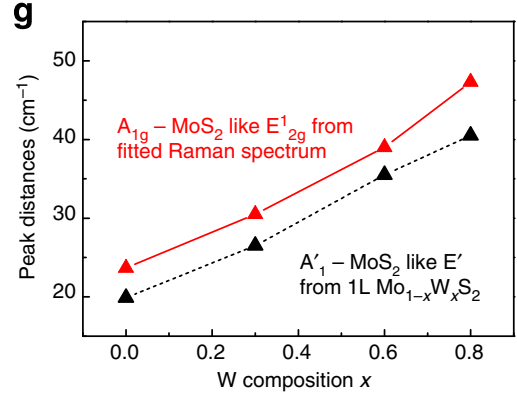

Figure 6 | Characterization of VCC $\mathbf{M o}_{1-\boldsymbol{x}} \mathbf{W}_{\mathbf{x}} \mathbf{S}_{\mathbf{2}}$ multilayer. (a) Sequential super-cycle ALD procedure and schematic structure of a VCC Mo ${ }_{1-x} \mathrm{~W}_{x} \mathrm{~S}_{2}$ multilayer. (b) AFM image and (c) height profiles (along with white dashed line in AFM image) for a VCC $\mathrm{Mo}_{1-x} \mathrm{~W}_{x} \mathrm{~S}_{2}$ multilayer. Scale bars, $0.5 \mu$ m. (d) Calculated atomic concentration and relative concentration ratio of Mo and W from ARXPS measurement. (e) Raman spectra for a VCC Mo ${ }_{1-x} \mathrm{~W}_{x} \mathrm{~S}_{2}$ multilayer. (f) Raman peak position of $A_{1 g}$ and $M_{0} S_{2}$-like $E_{2 g}^{1}$ modes from fitted Raman spectra (red and blue solid line) and from measured Raman spectra of $11 \mathrm{Mo}_{1-x} \mathrm{~W}_{x} \mathrm{~S}_{2}$ alloy (black dashed line). (g) Calculated Raman peak distances between $\mathrm{A}_{1 \mathrm{~g}}$ and $\mathrm{MoS}_{2}$-like $\mathrm{E}_{2 \mathrm{~g}}^{1}$ modes from fitted Raman spectra (red solid line) and from measured Raman spectra of $11 \mathrm{Mo}_{1-x} \mathrm{~W}_{x} \mathrm{~S}_{2}$ alloy (black dashed line).

W concentration. The $\mathrm{A}_{1 \mathrm{~g}}$ and $\mathrm{MoS}_{2}$-like $\mathrm{E}^{1}{ }_{2 \mathrm{~g}}$ peak positions from the fitted Raman spectrum are represented in Fig. $6 \mathrm{f}$ with the measured Raman peak positions for the $11 \mathrm{Mo}_{1-x} \mathrm{~W}_{x} \mathrm{~S}_{2}$ alloy (black dashed line, the same as Supplementary Fig. 7). The variation in the fitted Raman peak position with increasing $\mathrm{W}$ concentration in the $\mathrm{Mo}_{1-x} \mathrm{~W}_{x} \mathrm{~S}_{2}$ alloy is the same as the variation in the measured Raman peak position for the 11 $\mathrm{Mo}_{1-x} \mathrm{~W}_{x} \mathrm{~S}_{2}$ alloy: $\mathrm{A}_{1 \mathrm{~g}}$ shifts to a higher frequency with an increase in $\mathrm{W}$ concentration, while the $\mathrm{MoS}_{2}$-like $\mathrm{E}_{2 \mathrm{~g}}^{1}$ modes downshift. Figure $6 \mathrm{~g}$ shows peak distances between the $\mathrm{A}_{1 \mathrm{~g}}$ and $\mathrm{MoS}_{2}$-like $\mathrm{E}_{2 \mathrm{~g}}^{1}$ modes from the fitted Raman spectrum (red solid line) and measured Raman spectrum of the $11 \mathrm{Mo}_{1-x} \mathrm{~W}_{x} \mathrm{~S}_{2}$ alloy (black dashed line), which are $3-4 \mathrm{~cm}^{-1}$ larger than that of the Raman spectrum of the $11 \mathrm{Mo}_{1-}{ }_{x} \mathrm{~W}_{x} \mathrm{~S}_{2}$ alloy. This is due to the softening in the $\mathrm{MoS}_{2}$-like $\mathrm{E}_{2 \mathrm{~g}}^{1}$ mode frequency and stiffening in the $\mathrm{A}_{1 \mathrm{~g}}$ mode frequency. Similar behaviour, that is, increasing peak distances with increasing layer number, is also observed in $\mathrm{MoS}_{2}$ (refs 35,36) and $\mathrm{WS}_{2}$ (ref. 30) because of the reduced longrange Coulomb interaction between the effective charges, which is induced by an increase in the dielectric screening. These results for the fitted Raman spectra are in good agreement with the dependency of the peak positions on the $\mathrm{W}$ composition given by the measured Raman results, and the dependency of the peak distances on layer number in 2D TMDCs. Thus, we can conclude that the fitted Raman spectra show the formation of a $\mathrm{Mo}_{1-x} \mathrm{~W}_{x} \mathrm{~S}_{2}$ alloy with different compositions in a VCC $\mathrm{Mo}_{1-x} \mathrm{~W}_{x} \mathrm{~S}_{2}$ multilayer.

As a result, it can be stated that the ARXPS and Raman results show the VCC characteristics of a VCC $\mathrm{Mo}_{1-x} \mathrm{~W}_{x} \mathrm{~S}_{2}$ multilayer. Also, these findings indicate that the vertical interdiffusion of the Mo and $\mathrm{W}$ atoms during the sulfurization process have no critically effect on the VCC characteristics. A similar result was observed in a previous report, in that $\mathrm{MoO}_{x} / \mathrm{WO}_{3}$ thin film was converted to $\mathrm{MoS}_{2} / \mathrm{WS}_{2}$ without the formation of a $\mathrm{Mo}_{1-x} \mathrm{~W}_{x} \mathrm{~S}_{2}$ alloy, indicating the limited interdiffusion of Mo and W atoms ${ }^{46}$.
Further, it is noteworthy that we verified the validity of ARXPS and Raman measurements as a means of characterizing the VCC $\mathrm{Mo}_{1-x} \mathrm{~W}_{x} \mathrm{~S}_{2}$ multilayer via characterization of a VCC $\mathrm{Mo}_{1-x} \mathrm{~W}_{x} \mathrm{~S}_{2}$ multilayer synthesized with a reversed vertical composition profile (see Supplementary Fig. 10).

Since the interlayer coupling affects interlayer transition ${ }^{15,21,47,48}$, strong interlayer coupling in a synthesized VCC $\mathrm{Mo}_{1-x} \mathrm{~W}_{x} \mathrm{~S}_{2}$ multilayer was evaluated using comparison of interlayer transition in three difference sample types as shown in Fig. 7a. Sample 1 is a stacked VCC $\mathrm{Mo}_{1-x} \mathrm{~W}_{x} \mathrm{~S}_{2}$ multilayer fabricated by the transfer of each differently composed $\mathrm{Mo}_{1-x} \mathrm{~W}_{x} \mathrm{~S}_{2}$ alloy onto glass substrate, while sample 2 is the same as sample 1 but annealed at $200^{\circ} \mathrm{C}$ for $15 \mathrm{~min}$ in an $\mathrm{Ar}$ ambient atmosphere to enhance the interlayer coupling by the removal of residual molecules ${ }^{21,48}$. Sample 3 is a transferred VCC $\mathrm{Mo}_{1-} \mathrm{W}_{x} \mathrm{~S}_{2}$ multilayer on glass substrate, which was annealed at $200^{\circ} \mathrm{C}$ for $15 \mathrm{~min}$ in an $\mathrm{Ar}$ ambient atmosphere. Ultraviolet-visible spectrophotometer measurements for samples 1 , 2 and 3 (Fig. 7b) illustrate that these have broadband light absorption properties due to the sum of the light absorption from the differently composed $\mathrm{Mo}_{1-x} \mathrm{~W}_{x} \mathrm{~S}_{2}$ alloys. In previous reports, the absorption spectrum of the interlayer transition could be obtained by comparing the intensity difference between the absorption spectra of the weakly interlayer-coupled sample and that of the strongly interlayer-coupled sample ${ }^{15,48}$. Based on these reports, we extracted the interlayer transition absorption spectrum by subtracting the absorption spectrum of sample 1 from that of sample 2 and of sample 3 , since sample 1 has the weakest interlayer coupling of the three samples as a result of the contamination at the interface caused by the layer transfer process ${ }^{15,21,48}$. The extracted absorption spectra of the interlayer transition are shown in Fig. 7c. The sample 2-sample 1 spectrum (black solid line) shows a small absorbance peak at $1.87 \mathrm{eV}$, while the sample 3-sample 1 spectrum (red solid line) shows an absorbance peak that is over five times stronger than the sample 2-sample 1 absorbance peak at the same position. Specific observations on the origin of the absorbance peak 
a

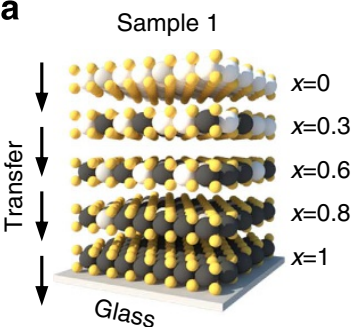

A stacked $\mathrm{VCC} \mathrm{Mo}_{1-x} \mathrm{~W}_{x} \mathrm{~S}_{2}$ multilayer

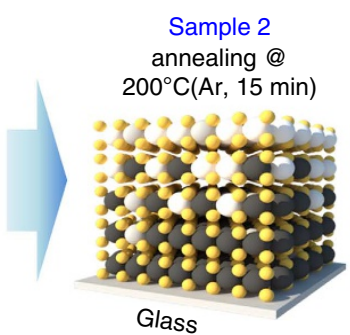

Annealed a stacked VCC $\mathrm{Mo}_{1-x} \mathrm{~W}_{x} \mathrm{~S}_{2}$ multilayer
Sample 3

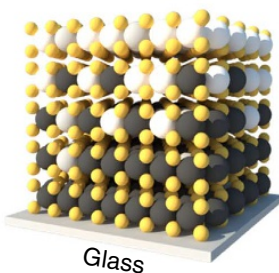

A VCC $\mathrm{Mo}_{1-x} \mathrm{~W}_{x} \mathrm{~S}_{2}$ multilayer

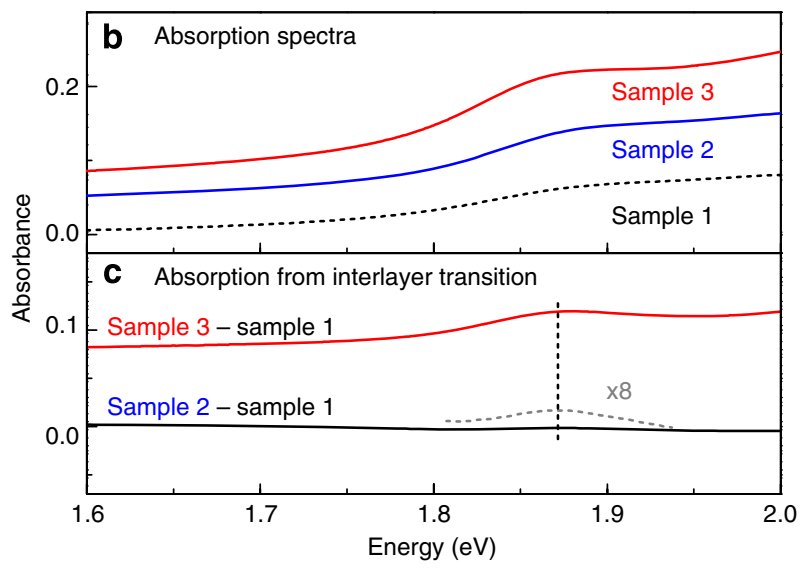

d

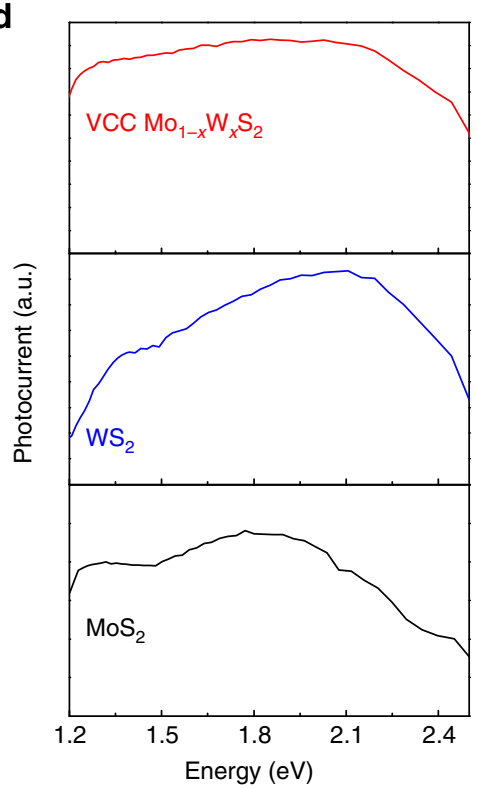

e

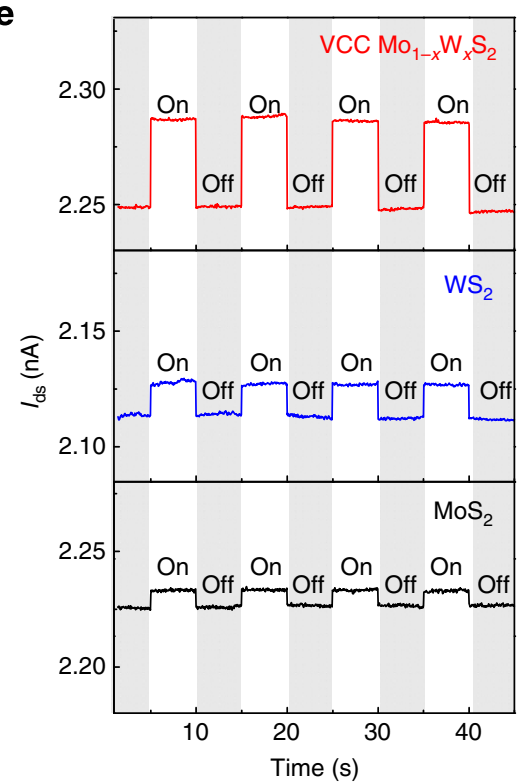

Figure $\mathbf{7}$ | Absorbance and photoinduced current of $\mathbf{V C C} \mathbf{M o}_{\mathbf{1}} \mathbf{W}_{\mathbf{x}} \mathbf{S}_{\mathbf{2}}$ multilayer. (a) Schematics of three sample types for ultraviolet-visible spectrophotometer measurement. (b) Absorption spectra of sample 1 (black solid line), sample 2 (blue solid line), and sample 3 (red solid line) and (c) extracted absorption spectra of interlayer transition using subtraction of sample 1 from sample 2 (black solid line) and from sample 3 (red solid line). (d) Spectral and (e) time-resolved photocurrent of a $\mathrm{VCC} \mathrm{Mo}_{1-x} \mathrm{~W}_{x} \mathrm{~S}_{2}$ multilayer, $5 \mathrm{I} \mathrm{WS}_{2}$ and $5 \mathrm{I} \mathrm{MoS}_{2}$ photodetectors.

position from the interlayer transition $(1.87 \mathrm{eV})$ are described in the Supplementary Information (Supplementary Fig. 11). The stronger absorbance peak of sample 3-sample 1 in comparison with that of sample 2-sample 1 indicates that sample 3 has stronger interlayer coupling compared with sample 2. In other words, a VCC $\mathrm{Mo}_{1-x} \mathrm{~W}_{x} \mathrm{~S}_{2}$ multilayer based on sequential super-cycle ALD has the strongest interlayer coupling among the three types of samples. We surmise that this strong interlayer coupling results from the absence of a transfer process, which eliminates the incorporation of residual molecules such as $\mathrm{H}_{2} \mathrm{O}$ and organic contaminants ${ }^{15,21,47,48}$.
A VCC $\mathrm{Mo}_{1-x} \mathrm{~W}_{x} \mathrm{~S}_{2}$ multilayer exhibits a broadband light absorption property, as well as strong interlayer coupling. Thus, the VCC $\mathrm{Mo}_{1-x} \mathrm{~W}_{x} \mathrm{~S}_{2}$ multilayer has promising potential use as an active layer in an efficient photodetector. To evaluate the photoinduced response of the VCC $\mathrm{Mo}_{1-x} \mathrm{~W}_{x} \mathrm{~S}_{2}$ multilayer, we observed the spectral and time-resolved photocurrent of a VCC $\mathrm{Mo}_{1-x} \mathrm{~W}_{x} \mathrm{~S}_{2}$ multilayer photodetector and compared it with 51 $\mathrm{WS}_{2}$ and $5 \mathrm{l} \mathrm{MoS}_{2}$ photodetectors (see the Methods section for details of device fabrication, and see Supplementary Fig. 12 for AFM images of the $51 \mathrm{MoS}_{2}$ and $\mathrm{WS}_{2}$ and their $I-V$ 
characteristics). Figure $7 \mathrm{~d}$ shows the dependence of the photocurrent on the illumination energy for the $\mathrm{VCC} \mathrm{Mo}_{1-x} \mathrm{~W}_{x} \mathrm{~S}_{2}$ multilayer, $5 \mathrm{l} \mathrm{WS}$, and $51 \mathrm{MoS}_{2}$ photodetectors for a voltage drain to source $\left(V_{\mathrm{ds}}\right)$ of $5 \mathrm{~V}$. The continuum power spectral density is represented in Supplementary Fig. 13. The VCC $\mathrm{Mo}_{1-x} \mathrm{~W}_{x} \mathrm{~S}_{2}$ multilayer photodetector generates a broadband photoinduced current from 1.2 to $2.5 \mathrm{eV}$, because of its broadband light absorption property. In contrast, the $51 \mathrm{WS}_{2}$ and $5 \mathrm{l}$ $\mathrm{MoS}_{2}$ photodetectors generate narrower photocurrents than the VCC $\mathrm{Mo}_{1-x} \mathrm{~W}_{x} \mathrm{~S}_{2}$ multilayer, at 1.3 and $2.1 \mathrm{eV}$ for the $5 \mathrm{WS}_{2}$ photodetector and 1.2 and $1.8 \mathrm{eV}$ for the $\mathrm{MoS}_{2}$ device; these values correspond to the $51 \mathrm{WS}_{2}$ and $\mathrm{MoS}_{2}$ bandgaps. We then examined the time-resolved photocurrent measurement using white-light illumination, as shown in Fig. 7e (result using specific laser wavelength is shown in Supplementary Fig. 14). The white light was first turned off for a period of $5 \mathrm{~s}$, and then turned on for $5 \mathrm{~s}$ with the biasing $V_{\mathrm{ds}}=5 \mathrm{~V}$. The drain current $\left(I_{\mathrm{ds}}\right)$ increased on activation of the light and decayed following removal of the incident light. The induced photocurrents were $39 \mathrm{pA}, 13 \mathrm{pA}$ and $11 \mathrm{pA}$ for the VCC $\mathrm{Mo}_{1-x} \mathrm{~W}_{x} \mathrm{~S}_{2}$ multilayer, 5l WS $\mathrm{W}_{2}$ and $5 \mathrm{l} \mathrm{MoS}$ devices, respectively. Hence, the VCC $\mathrm{Mo}_{1-x} \mathrm{~W}_{x} \mathrm{~S}_{2}$ multilayer generates three to four times greater photocurrent than $5 \mathrm{WWS}_{2}$ or $51 \mathrm{MoS}_{2}$, which is attributed to broadband light absorption. Thus, we concluded that the VCC $\mathrm{Mo}_{1-x} \mathrm{~W}_{x} \mathrm{~S}_{2}$ multilayer is promising as regards use as an efficient photodetector with broadband light absorption. Furthermore, the broadband light absorption property is feasible for various optoelectronic applications such as solar cells ${ }^{49,50}$.

\section{Discussion}

In summary, we developed an ALD-based $\mathrm{Mo}_{1-x} \mathrm{~W}_{x} \mathrm{~S}_{2}$ synthesis process using sulfurization of super-cycle ALD $\mathrm{Mo}_{1-x} \mathrm{~W}_{x} \mathrm{O}_{y}$ thin film. We studied the sulfurization process of ALD $\mathrm{MoO}_{x}$ thin films to produce uniform and continuous $\mathrm{MoS}_{2}$. The synthesized ALD-based $\mathrm{Mo}_{1-x} \mathrm{~W}_{x} \mathrm{~S}_{2}$ alloy show good stoichiometry, uniform and continuous surfaces, controlled composition and layer numbers, and mixing of $\mathrm{Mo}$ and $\mathrm{W}$ atoms. Moreover, we developed a simple method to synthesize a VCC $\mathrm{Mo}_{1-x} \mathrm{~W}_{x} \mathrm{~S}_{2}$ multilayer with a clean interface, which shows stronger interlayer coupling than that of a stacked $\mathrm{VCC} \mathrm{Mo}_{1-x} \mathrm{~W}_{x} \mathrm{~S}_{2}$ multilayer fabricated using the transfer process. Further, we have shown that the $\mathrm{VCC} \mathrm{Mo}_{1-x} \mathrm{~W}_{x} \mathrm{~S}_{2}$ multilayer has promising potential applications as an efficient photodetector, because of its broadband light absorption capability. It should also be noted that the ALD-based TMDCs alloy synthesis process is not only limited to $\mathrm{Mo}_{1-x} \mathrm{~W}_{x} \mathrm{~S}_{2}$, and we expect that similar process strategies can be developed for other TMDCs materials and their vertical stacks.

\footnotetext{
Methods

$\mathbf{M o O}_{x}$ film growth and characteristics. A 6-inch ALD chamber containing a loadlock chamber was used for the deposition of the $\mathrm{MoO}_{x}$ films. The films were deposited on $\mathrm{SiO}_{2}(300 \mathrm{~nm}) / \mathrm{Si}$ substrates by plasma-enhanced $\mathrm{ALD}$ using $\mathrm{Mo}(\mathrm{CO})_{6}$ and $\mathrm{O}_{2}$ plasma at a $200^{\circ} \mathrm{C}$ growth temperature. The temperature of the bubbler containing $\mathrm{Mo}(\mathrm{CO})_{6}$ was maintained at $35^{\circ} \mathrm{C}$ to produce adequate vapour pressure, and vapourized $\mathrm{Mo}(\mathrm{CO})_{6}$ molecules were transported into the chamber by pure argon $(99.999 \%)$ carrier gas. The $\mathrm{O}_{2}$ flow and plasma power were fixed at 300 s.c.c.m. and $200 \mathrm{~W}$, respectively. An ALD cycle consists of four steps: $\mathrm{Mo}(\mathrm{CO})_{6}$ precursor exposure $\left(t_{\mathrm{s}}\right)$, Ar purging $\left(t_{\mathrm{p}}\right), \mathrm{O}_{2}$ plasma reactant exposure $\left(t_{\mathrm{r}}\right)$ and another Ar purging $\left(t_{\mathrm{p}}\right)$. In the ALD $\mathrm{MoO}_{x}$ process, the $t_{\mathrm{s}}, t_{\mathrm{p}}$ and $t_{\mathrm{r}}$ were fixed at $5 \mathrm{~s}$, $12 \mathrm{~s}$ and $5 \mathrm{~s}$, respectively. Optimization of the ALD $\mathrm{MoO}_{x}$ process is described in the Supplementary Fig. 1.
}

$\mathbf{M o}_{{ }_{-x}} \mathbf{W}_{\mathbf{x}} \mathbf{O}_{\mathbf{y}}$ Film Growth. $\mathrm{MoO}_{x}$ and $\mathrm{WO}_{3}$ ALD processes ${ }^{27}$ were used to deposit $\mathrm{Mo}_{1-x} \mathrm{~W}_{x} \mathrm{O}_{y}$ film using super-cycle ALD (as shown in Fig. 3a) under the same chamber and deposition conditions described above for the ALD of $\mathrm{MoO}_{x}$. After 10 cycles of $\mathrm{WO}_{3} \mathrm{ALD}$ to address nucleation delay ${ }^{27}$, we conducted super-cycle ALD, which consists of $n$ cycles of $\mathrm{MoO}_{x} \mathrm{ALD}$ and $m$ cycles of $\mathrm{WO}_{3} \mathrm{ALD}$. The detailed process steps are shown in Supplementary Table 1.
Sulfurization processes. One-step process. To sulfurize the ALD $\mathrm{MoO}_{x}$, the sample was placed in the centre of a tube furnace (1.2 inch in diameter). Initially, the sample was heated at $200^{\circ} \mathrm{C}$ for $60 \mathrm{~min}$ under flowing $\mathrm{H}_{2}$ (25 s.c.c.m.) and $\mathrm{Ar}$ ( 25 s.c.c.m.) gas, to remove any organic contaminants on the surface. Subsequently, the temperature was gradually increased from 200 to $1,000{ }^{\circ} \mathrm{C}$ at $13.3{ }^{\circ} \mathrm{C} \mathrm{min}{ }^{-1}$, and this temperature was then maintained for $60 \mathrm{~min}$ with flowing $\operatorname{Ar}(50$ s.c.c.m.) and $\mathrm{H}_{2} \mathrm{~S}$ ( 5 s.c.c.m.). Then, the sample was cooled to room temperature under a flowing $\operatorname{Ar}(50$ s.c.c.m.) atmosphere.

Two-step process. Initially, samples were annealed at $200^{\circ} \mathrm{C}$ as in the one-step process. Then, the temperature was gradually increased from $200^{\circ} \mathrm{C}$ to firstsulfurization temperatures of 600 or $800^{\circ} \mathrm{C}$ at $13.3^{\circ} \mathrm{C} \mathrm{min}^{-1}$. The peak temperature $\left(600\right.$ or $\left.800^{\circ} \mathrm{C}\right)$ was maintained for $60 \mathrm{~min}$ with flowing $\mathrm{Ar}$ (50 s.c.c.m.) and $\mathrm{H}_{2} \mathrm{~S}$ (5 s.c.c.m.). Subsequently, the temperature was gradually increased from the first-sulfurization temperatures to $1,000^{\circ} \mathrm{C}$ at $13.3^{\circ} \mathrm{C} \mathrm{min}-1$ and was maintained at this temperature for $30 \mathrm{~min}$ with flowing $\mathrm{Ar}$ ( 50 s.c.c.m.) and $\mathrm{H}_{2} \mathrm{~S}$ (5 s.c.c.m.). The sample was cooled to room temperature under a flowing $\mathrm{Ar}(50$ s.c.c.m.) atmosphere after the process was completed. Based on the results shown in Fig. 1, we used a two-step sulfurization process with a $600^{\circ} \mathrm{C}$ firstsulfurization temperature to sulfurize $\mathrm{MoO}_{x}$ and $\mathrm{Mo}_{1-x} \mathrm{~W}_{x} \mathrm{O}_{y}$ thin films in the $\mathrm{MoS}_{2}$ and $\mathrm{Mo}_{1-x} \mathrm{~W}_{x} \mathrm{~S}_{2}$ alloy synthesis process.

Transfer of $\mathbf{M o S}_{\mathbf{2}}$ and $\mathbf{M o}_{1-x} \mathbf{W}_{\mathbf{x}} \mathbf{S}_{\mathbf{2}}$. The as-synthesized $\mathrm{MoS}_{2}$ and $\mathrm{Mo}_{1-x} \mathrm{~W}_{x} \mathrm{~S}_{2}$ on the $\mathrm{SiO}_{2}$ substrate were coated with polymethyl methacrylate (PMMA) by spin coating at 4,000 r.p.m. for $60 \mathrm{~s}$. After curing of the PMMA at $100^{\circ} \mathrm{C}$ for $15 \mathrm{~min}$, the samples were immersed in $10 \%$ hydrogen fluoride solution to etch the $\mathrm{SiO}_{2}$ layer Subsequently, the samples were washed using deionized (DI) water and scooped onto a clean $\mathrm{SiO}_{2} / \mathrm{Si}$ substrate. The PMMA was removed by acetone and washed away using isopropyl alcohol.

Characterization of $\mathbf{M o S}_{\mathbf{2}}$ and $\mathbf{M o}_{\mathbf{1}} \mathbf{W}_{\mathbf{x}} \mathbf{S}_{\mathbf{2}}$. OM (Olympus DX51), Raman spectroscopy (HORIBA, Lab Ram ARAMIS; 532-nm laser excitation wavelength), AFM (VEECO, Multimode), PL (SPEX1403, SPEX; 532-nm laser excitation wavelength), absorbance with ultraviolet-visible spectrophotometer (JASCO Corporation, V-650), XPS (Thermo UK, K-alpha), SEM (JEOL Ltd, JSM-6701F), TEM (FEI Titan G2 Cube 60-300; accelerating voltage, $80 \mathrm{kV}$ ), STEM and EDX (JEM 2100F; accelerating voltage, $200 \mathrm{kV}$ ) analyses were employed to characterize the $\mathrm{MoS}_{2}$ and $\mathrm{Mo}_{1-x} \mathrm{~W}_{x} \mathrm{~S}_{2}$ alloy, and a VCC $\mathrm{Mo}_{1-x} \mathrm{~W}_{x} \mathrm{~S}_{2}$ multilayer.

Fabrication and characterization of photodetectors. Photodetectors were fabricated from an as-synthesized VCC $\mathrm{Mo}_{1-x} \mathrm{~W}_{x} \mathrm{~S}_{2}$ multilayer, $51 \mathrm{WS}_{2}$ and 51 $\mathrm{MoS}_{2}$ on a $\mathrm{SiO}_{2}(300 \mathrm{~nm}) / \mathrm{Si}$ substrate by evaporating $\mathrm{Au}(40 \mathrm{~nm}) / \mathrm{Ti}(1 \mathrm{~nm})$ electrodes with $100-\mu \mathrm{m}$ channel length. Electrical measurements were conducted using a Keithley 2400 (Keithley Instruments). The photocurrent was measured by modulating the laser beam with a mechanical chopper $(1,000 \mathrm{~Hz})$ and detecting the photocurrent with a current preamplifier and a lock-in amplifier. A monochromator was used for wavelength-dependent measurements of the photocurrent.

Parameters for analysis of XPS and Raman. We used Spectral Data Processor v4.1 for the XPS and Raman spectra fitting. In the fitting analysis of the XPS spectra, the full widths at half maximum (FWHM) were between 1.7 and $1.9 \mathrm{eV}$, the Lorentzian Gaussian Ratio was 2:8, the energy difference between the Mo3d spin-orbit doublet was set to $3.2 \mathrm{eV}$ and the branching ratio was $2 / 3$. In addition, we used Scofield Relative Sensitivity Factor for calculation of stoichiometry as represented in Supplementary Table 2. For the Raman spectrum fitting analysis, the FWHM was between 7 and $12 \mathrm{~cm}^{-1}$

\section{References}

1. Bernardi, M. et al. Extraordinary sunlight absorption and $1 \mathrm{~nm}$-thick photovoltaics using two-dimensional monolayer materials. Nano Lett. 13, 3664-3670 (2013).

2. Wang, Q. H. et al. Electronics and optoelectronics of two-dimensional transition metal dichalcogenides. Nat. Nanotechnol. 7, 699-712 (2012).

3. Chhowalla, M. et al. The chemistry of two-dimensional layered transition metal dichalcogenide nanosheets. Nat. Chem. 5, 263-275 (2013).

4. Eda, G. et al. Photoluminescence from chemically exfoliated $\mathrm{MoS}_{2}$. Nano Lett 11, 5111-5116 (2011).

5. Mak, K. et al. Atomically thin $\mathrm{MoS}_{2}$ : a new direct-gap semiconductor. Phys. Rev. Lett. 105, 136805 (2010).

6. Lee, H. S. et al. $\mathrm{MoS}_{2}$ nanosheet phototransistors with thickness-modulated optical energy gap. Nano Lett. 12, 3695-3700 (2012).

7. Liu, H. et al. Vapor-phase growth and characterization of $\mathrm{Mo}_{1-\mathrm{x}} \mathrm{W}_{\mathrm{x}} \mathrm{S}_{2}(0 \leq \mathrm{x} \leq 1)$ atomic layers on 2-inch sapphire substrates. Nanoscale 6, 624-629 (2014).

8. Chen, Y. et al. Composition-dependent raman modes of $\mathrm{Mo}_{1-\mathrm{x}} \mathrm{W}_{\mathrm{x}} \mathrm{S}_{2}$ monolayer alloys.. Nanoscale 6, 2833-2839 (2014).

9. Chen, Y. et al. Tunable band gap photoluminescence from atomically thin transition-metal dichalcogenide alloys. ACS Nano 7, 4610-4616 (2013) 
10. Wei, X.-L. et al. Modulating the atomic and electronic structures through alloying and heterostructure of single-layer $\mathrm{MoS}_{2}$. J. Mater. Chem. A 2, 2101-2109 (2014).

11. Feng, Q. et al. Growth of large-area $2 \mathrm{D} \mathrm{MoS}_{2(1-\mathrm{x})} \mathrm{Se}_{2 \mathrm{x}}$ semiconductor alloys. Adv. Mater. 26, 2648-2653 (2014).

12. Xi, J. et al. Tunable electronic properties of two-dimensional transition metal dichalcogenide alloys: a first-principles prediction. J. Phys. Chem. Lett. 5, 285-291 (2013)

13. Lin, Z. et al. Facile synthesis of MoS2 and MoxW1-xS2 triangular monolayers. APL Mater. 2, 092514 (2014).

14. Tannous, J. et al. Synthesis and tribological performance of novel MoxW1 - xS2 $(0 \leq \mathrm{x} \leq 1)$ inorganic fullerenes. Tribol. Lett. 37, 83-92 (2010).

15. Yu, Y. et al. Equally efficient interlayer exciton relaxation and improved absorption in epitaxial and non-epitaxial MoS2/WS2 heterostructures. Nano Lett. 15, 486-491 (2015).

16. Hong, X. et al. Ultrafast charge transfer in atomically thin $\mathrm{MoS}_{2} / \mathrm{WS}_{2}$ heterostructures. Nat. Nanotechnol. 9, 682-686 (2014).

17. Kośmider, K. et al. Electronic properties of the $\mathrm{MoS}_{2}-\mathrm{WS}_{2}$ heterojunction. Phys. Rev. B 87, 075451 (2013).

18. Huo, N. et al. Novel and enhanced optoelectronic performances of multilayer $\mathrm{MoS}_{2}-\mathrm{WS}_{2}$ heterostructure transistors. Adv. Funct. Mater. 24, 7025-7031 (2014).

19. Jung, Y. et al. Chemically synthesized heterostructures of two-dimensional molybdenum/tungsten-based dichalcogenides with vertically aligned layers. ACS Nano 8, 9550-9557 (2014).

20. Cheng, R. et al. Electroluminescence and photocurrent generation from atomically sharp $\mathrm{WSe}_{2} / \mathrm{MoS}_{2}$ heterojunctionpn diodes. Nano Lett. 14, 5590-5597 (2014)

21. Tongay, S. et al. Tuning interlayer coupling in large-area heterostructures with CVD-grown $\mathrm{MoS}_{2}$ and $\mathrm{WS}_{2}$ monolayers. Nano Lett. 14, 3185-3190 (2014).

22. Terrones, H., López-Urías, F. \& Terrones, M. Novel hetero-layered materials with tunable direct band gaps by sandwiching different metal disulfides and diselenides. Sci. Rep. 3, 1549 (2013).

23. Gong, Y. et al. Band gap engineering and layer-by-layer mapping of selenium-doped molybdenum disulfide. Nano Lett. 14, $442-449$ (2013).

24. Hyungjun, K. Characteristics and applications of plasma enhanced-atomic layer deposition. Thin Solid Films 519, 6639-6644 (2011)

25. Kim, H. et al. Applications of atomic layer deposition to nanofabrication and emerging nanodevices. Thin Solid Films 517, 2563-2580 (2009).

26. Lee, J.-S. et al. Atomic layer deposition of $\mathrm{Y}_{2} \mathrm{O}_{3}$ and yttrium-doped $\mathrm{HfO}_{2}$ using a newly synthesized $\mathrm{Y}(\mathrm{iPrCp})_{2}(\mathrm{~N}$-iPr-amd) precursor for a high permittivity gate dielectric. Appl. Surf. Sci. 297, 16-21 (2014).

27. Nam, T. et al. Growth characteristics and properties of Ga-doped $\mathrm{ZnO}(\mathrm{GZO})$ thin films grown by thermal and plasma-enhanced atomic layer deposition. Appl. Surf. Sci. 295, 260-265 (2014).

28. Kim, W. H. et al. Significant enhancement of the dielectric constant through the doping of $\mathrm{CeO}_{2}$ into $\mathrm{HfO}_{2}$ by atomic layer deposition. J. Am. Ceram. Soc. 97, 1164-1169 (2014).

29. Brahim, C. et al. $\mathrm{ZrO} 2-\mathrm{In} 2 \mathrm{O} 3$ thin layers with gradual ionic to electronic composition synthesized by atomic layer deposition for SOFC applications. J. Mater. Chem. 19, 760-766 (2009).

30. Song, J.-G. et al. Layer-controlled, wafer-scale, and conformal synthesis of tungsten disulfide nanosheets using atomic layer deposition. ACS Nano 7, 11333-11340 (2013).

31. Blackburn, P. E. et al. The vaporization of molybdenum and tungsten oxides. J. Phys. Chem. 62, 769-773 (1958).

32. Gutiérrez, H. R. et al. Extraordinary room-temperature photoluminescence in triangular $\mathrm{WS}_{2}$ monolayers. Nano Lett. 13, 3447-3454 (2013).

33. Lin, Y.-C. et al. Wafer-scale $\mathrm{MoS}_{2}$ thin layers prepared by $\mathrm{MoO}_{3}$ sulfurization. Nanoscale 4, 6637-6641 (2012).

34. Terrones, H. et al. New first order Raman-active modes in few layered transition metal dichalcogenides. Sci. Rep. 4, 4215 (2014).

35. Li, S.-L. et al. Quantitative raman spectrum and reliable thickness identification for atomic layers on insulating substrates. ACS Nano 6, 7381-7388 (2012).

36. Li, H. et al. From bulk to monolayer $\mathrm{MoS}_{2}$ : evolution of Raman scattering. $A d v$. Funct. Mater. 22, 1385-1390 (2012).

37. Ling, X. et al. Role of the seeding promoter in $\mathrm{MoS}_{2}$ growth by chemical vapor deposition. Nano Lett. 14, 464-472 (2014).
38. Schmidt, H. et al. Transport properties of monolayer $\mathrm{MoS}_{2}$ grown by chemical vapor deposition. Nano Lett. 14, 1909-1913 (2014).

39. Yu, Y. et al. Controlled scalable synthesis of uniform, high-quality monolayer and few-layer $\mathrm{MoS}_{2}$ films. Sci. Rep. 3, 1866 (2013).

40. Splendiani, A. et al. Emerging photoluminescence in monolayer MoS2. Nano Lett. 10, 1271-1275 (2010).

41. Lee, Y. et al. Synthesis of wafer-scale uniform molybdenum disulfide films with control over the layer number using a gas phase sulfur precursor. Nanoscale 6 , 2821-2826 (2014).

42. Van Vechten, J. et al. Electronic structures of semiconductor alloys. Phys. Rev. B 1, 3351 (1970).

43. Yin, W.-J. et al. Origin of the unusually large band-gap bowing and the breakdown of the band-edge distribution rule in the $\mathrm{Sn}_{\mathrm{x}} \mathrm{Ge}_{1-\mathrm{x}}$ alloys. Phys. Rev. B 78, 161203 (2008)

44. Dumcenco, D. O. et al. Visualization and quantification of transition metal atomic mixing in $\mathrm{Mo}_{1-}{ }_{\mathrm{x}} \mathrm{W}_{\mathrm{x}} \mathrm{S}_{2}$ single layers. Nat. Commun. 4, 1351 (2013).

45. Garcia, A. et al. Analysis of electron beam damage of exfoliated $\mathrm{MoS}_{2}$ sheets and quantitative HAADF-STEM imaging. Ultramicroscopy 146, 33-38 (2014)

46. Elías, A. L. et al. Controlled synthesis and transfer of large-area $\mathrm{WS}_{2}$ sheets: from single layer to few layers. ACS Nano 7, 5235-5242 (2013).

47. Gong, Y. et al. Vertical and in-plane heterostructures from $\mathrm{WS}_{2} / \mathrm{MoS}_{2}$ monolayers. Nat. Mater. 13, 1135-1142 (2014).

48. Chiu, M.-H. et al. Spectroscopic signatures for interlayer coupling in $\mathrm{MoS}_{2}-\mathrm{WSe}{ }_{2}$ van der Waals stacking. ACS Nano 8, 9649-9656 (2014).

49. Lin, Q. et al. Efficient light absorption with integrated nanopillar/nanowell arrays for three-dimensional thin-film photovoltaic applications. ACS Nano 7, 2725-2732 (2013).

50. Aydin, K. et al. Broadband polarization-independent resonant light absorption using ultrathin plasmonic super absorbers. Nat. Commun. 2, 517 (2011).

\section{Acknowledgements}

This work was supported by the Center for Integrated Smart Sensors funded by the Ministry of Science, ICT \& Future Planning as Global Frontier Project (CISS-20110031848), the National Research Foundation of Korea(NRF) grant funded by the Korea government(MSIP) (No. NRF-2014R1A2A1A11052588 and 2011-0013255), and Korea Evaluation Institute of Industrial Technology (KEIT) funded by the Ministry of Trade, Industry and Energy (MOTIE) (Project No. 10050296, Large scale (Over 8) synthesis and evaluation technology of $2 \mathrm{D}$ chalcogenides for next generation electronic devices).

\section{Author contributions}

J.-G.S. carried out most experiments and analysed the data. G.H.R. and Z.L. contributed to TEM measurement. S.J.L. and J.-M.M. contributed to PL measurement. S.W.S and H.C contributed to photoresponse measurement. C.W.L. contributed to XPS measurement. T.C., H.J. and Y.K. contributed to Raman and AFM measurement. C.D. and C.L.-M. contributed to development and handling of ALD precursor. J.-G.S., J.P. and H.K. designed the experiment and co-wrote the paper. All of the authors discussed the results and commented on the paper.

\section{Additional information}

Supplementary Information accompanies this paper at http://www.nature.com/ naturecommunications

Competing financial interests: The authors declare no competing financial interests

Reprints and permission information is available online at http://npg.nature.com/ reprintsandpermissions/

How to cite this article: Song, J. G. et al. Controllable synthesis of molybdenum tungsten disulfide alloy for vertically composition-controlled multilayer. Nat. Commun. 6:7817 doi: $10.1038 /$ ncomms8817 (2015).

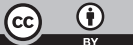

This work is licensed under a Creative Commons Attribution 4.0 International License. The images or other third party material in this article are included in the article's Creative Commons license, unless indicated otherwise in the credit line; if the material is not included under the Creative Commons license, users will need to obtain permission from the license holder to reproduce the material To view a copy of this license, visit http://creativecommons.org/licenses/by/4.0/ 